\title{
Study on Stressing State and Failure Criterion of Concrete-Filled Stainless Steel and Steel Tubular Column
}

\author{
Baisong Yang,, ${ }^{1,2}$ Wei Wang, ${ }^{3}$ Lingxian Yang, ${ }^{1,2}$ Guorui Sun, ${ }^{1,2}$ and Sijin Liu $\mathbb{D}^{4}$ \\ ${ }^{1}$ Key Lab of Structures Dynamic Behavior and Control of the Ministry of Education, Harbin Institute of Technology, \\ Harbin 150090, China \\ ${ }^{2}$ Key Lab of Smart Prevention and Mitigation of Civil Engineering Disasters of the Ministry of Industry and \\ Information Technology, Harbin Institute of Technology, Harbin 150090, China \\ ${ }^{3}$ Academy of Combat Support, Rocket Force University of Engineering, Xi'an 710025, China \\ ${ }^{4}$ China Railway 14th Bureau Group Co., Ltd., Jinan, China
}

Correspondence should be addressed to Sijin Liu; ahlsj@126.com

Received 26 March 2020; Accepted 16 June 2020; Published 20 July 2020

Academic Editor: Jiang Jin

Copyright ( 12020 Baisong Yang et al. This is an open access article distributed under the Creative Commons Attribution License, which permits unrestricted use, distribution, and reproduction in any medium, provided the original work is properly cited.

In this paper, the mechanical characteristics of concrete-filled stainless steel and steel tubular (CFSSAST) columns under axial and eccentric loads are analyzed by using the theory of structural stressing state. Firstly, the sum of generalized strain energy density (GSED) values of the short column at every load value $\left(F_{j}\right)$ is normalized as $E_{j, \text { norm }}$ to describe the structural stressing state. Then, according to Mann-Kendall (M-K) criterion and the natural law from quantitative change to qualitative change, the transition of stressing state is distinguished, which leads to the update of failure load. Then, the corresponding finite element models are established, and the accuracy of the models is verified by the experimental data, and the stress contour maps are analyzed by simulation data. Finally, the simulation data are used to perform parameter analysis. This study explores a new method to reveal the invisible working characteristics of structures and provides a new reference for the study of similar structures.

\section{Introduction}

The structure concrete-filled stainless steel and steel tubular (CFSSAST) column is a new combined structure developed on the basis of the traditional concrete filled double-skin steel tubular (CFDSST) columns. This kind of composite structure not only inherits the advantages of high bearing capacity, good toughness, good fire resistance, high bending rigidity, and light weight, but also has good corrosion resistance and durability due to the use of stainless steel. And it can be widely applied in structures such as cross-sea bridge structures and offshore platforms that require high resistance to corrosion.

As a kind of special concrete filled double-skin steel tubular, the mechanical properties of CFSSAST components are very similar to those of ordinary CFDSST columns. Therefore, the research on ordinary CFDSST columns could provide significant and valuable references.
Tao conducted a series of experiments on concrete-filled double skin steel tubular stub columns (fourteen) and beam-columns (twelve), providing practical checking method for the bearing capacities of the composite columns [1]. Zhao and Wei derived the unified calculation formula of bearing capacity of CFDSST components subjected to axial compressive loading based on the Twin Shear Unified Strength Theory [2]. Zhang et al. carried out the experiment on the short CFDSST columns with different eccentricity. The results indicated that, with the increase of eccentricity, the ultimate bearing capacity of short column obviously decreased, and its lateral deformation capacity weakened, while the eccentricity has little effect on the ductility of short column [3]. Ren et al. conducted a finite element (FE) analysis of the compressive behavior of circular inclined concrete-filled steel tubular stub columns and verified the FE method by experimental data. The result showed that the FE method is available for 
predicting the bearing capacities of the circular inclined specimens [4]. Li et al. established a general finite element analysis model of CFDSST columns under preloading and proposed corresponding formulas for calculating the ultimate bearing capacity of CFDSST columns with preloading on steel tubes [5]. Subsequently, many researchers had studied the axial compression performance of CFDSST columns [6-8]. Hassanein and Kharoob summarized previously developed formulas for predicting the compressive strength of the CFDSST columns and used the ABAQUS/standard software to perform numerical nonlinear simulations. Through comparing tested results with simulated results, a new design formula is suggested [9]. Liang established a new mathematical model, which could compute the axial load-deflection performance of high-strength circular CFDSST slender columns subjected to eccentric loading. The model accurately predicted the residual concrete strength and strain in the postyield regime [10].

In recent years, many scholars had conducted experimental research on concrete-filled stainless steel and steel tubular (CFSSAST) columns. For instances, Han et al. conducted a series of performance tests on CFSSAST columns and proposed a simplified model for predicting the strength of the column section [11]. Chang et al. carried out a range of compression tests on CFSSAST columns. The results indicated that the column strength increased with the increasing of the diameter ratio, wall thickness ratio, yield strength ratio, and concrete strength [12]. Cao took the shear span ratio of CFSSAST columns as the main variable parameter and carried out bending tests. The results showed that the CFSSAST specimens exhibited outstanding ductile damage performance under bending load, and the flexural capacity was inversely proportional to the shear span ratio [13]. Zhou and $\mathrm{Xu}$ conducted cyclic load test on double-layer stainless steel tube concrete beam column. The results showed that the axial compressive load level and thickness of outer tubes have a primary influence on the behavior of the test specimens [14]. Wen conducted an experimental study on the mechanical behavior of CFSSAST columns. The experiment results indicated that, for long columns under eccentric loading conditions, the stiffness and bearing capacity decreased obviously with the increase of the hollow ratio, slenderness ratio, and load eccentricity [15]. Zhang et al. carried out the experimental research on the shear resistance performance of concrete-filled double stainless-steel tubular columns and proposed empirical equation for calculating the shear bearing capacity of specimens [16]. Some other researchers tested the impact resistance of CFSSAST columns $[17,18]$. The experimental results showed that the global deformation and local deformation of specimens developed with the increase of the impact force, the impact time, and impact height.

Although these research results greatly promoted the application of CFSSAST columns in engineering projects, there are still some problems of CFSSAST columns to be resolved, summarized as follows: (1) Up to now, the failure load of CFSSAST columns is determined on the semiempirical and semitheoretical basis with considerable inaccuracy, and the failure mechanism of the columns is not involved. (2) At present, most of the researches tend to focus on the mechanical properties of CFSSAST columns under axial loads, while the researches of specimens under eccentric loads are inadequate.

In order to address these two issues, the authors deeply study the mechanical properties of CFSSAST columns under axial and eccentric loads, based on the theory of structural stressing states. The measured strain data of CFSSAST columns are modeled as generalized strain energy density (GSED) to describe the structural stressing state modes. Then M-K method is applied to GSED sum-load curve to distinguish the mutation feature of the curve and reveal the failure mechanism of CFSSAST columns in the process of loading, so as to update the definition of the existing column failure load.

\section{Methods for Modelling and Analyzing Structural Stressing State}

2.1. Structural Stressing State Concept and GSED Curve. The authors define the stressing state of a structure as the structural working behavior characterized by the distribution pattern of strain energy density values, displacements, strains, and stresses of measuring points $[19,20]$. Generally, the strain energy density $E_{i}$ of the $i$-th point can be calculated by

$$
E_{i}=\int \sigma_{1} d \varepsilon_{1}+\sigma_{2} d \varepsilon_{2}+\sigma_{3} d \varepsilon_{3}
$$

where $\sigma_{1}, \sigma_{2}, \sigma_{3}$ and $\varepsilon_{1}, \varepsilon_{2}, \varepsilon_{3}$ are three principal stresses and strains, respectively; $E_{i}$ is the $i$-th strain energy density. However, due to the directionality of stress and strain, this numerical model is not convenient for further processing and analysis. Therefore, the generalized strain energy density (GSED) is used as the parameter to characterize the stressing state at a certain point. Thus, equation (1) is simplified as

$$
E_{i j}=\frac{1}{2} E \varepsilon_{i j}^{2}
$$

where $E_{i j}$ is the GSED value of the $i$-th measured point under the $j$-th load; $E$ is the elastic modulus of the material; $\varepsilon_{i j}$ is the strain value of the $i$-th point under the $j$-th load. In order to better compare and analyze the change characteristics of GSED sum curve of different components or structures, it can be normalized as

$$
E_{j, \text { norm }}=\frac{\sum_{i=1}^{N} E_{i j}}{E_{\max }}
$$

where $E_{j \text {,norm }}$ is the sum of the normalized GSED values of all the measured points to the $j$-th load; $N$ is the number of all measuring points; $E_{\max }$ is the maximum of the strain energy values over the loading process. Thus, the $E_{j, \text { norm }}-F_{j}$ curve of the structure can be plotted to investigate different structural stressing states and corresponding characteristics.

2.2. M-K Criterion. The Mann-Kendall (M-K) method is applied to distinguish the stressing state mutation of the structure through the $E_{j, \text { norm }}-F_{j}$ curve, because it does not 
need the sample to obey some distributions or be interfered by some outliers. For this study, it is assumed that the sequence of $\left\{E^{\prime}(i)\right\}$ (the load step $\left.i=1,2, \ldots, n\right)$ is statistically independent. Then, a new stochastic variable $b_{m}$ at the $m$-th load step is defined as

$$
b_{m}=\sum_{i}^{m} h_{i}(2 \leq m \leq n), h_{i}= \begin{cases}+1, & E^{\prime}(i)>E^{\prime}(j)(1 \leq j \leq i), \\ 0, & \text { otherwise }\end{cases}
$$

where $h_{i}$ is the cumulative number of the samples; "+1" means adding one more to the existing value if the inequality on the right side is satisfied for the $j^{\text {th }}$ comparison. The mean value $D\left(b_{m}\right)$ and variance $\operatorname{Var}\left(b_{m}\right)$ of $b_{m}$ are calculated by

$$
\begin{gathered}
D\left(b_{m}\right)=\frac{m(m-1)}{4}, \quad 2 \leq m \leq n, \\
\operatorname{Var}\left(b_{m}\right)=\frac{m(m-1)(2 m+5)}{72}, \quad 2 \leq m \leq n .
\end{gathered}
$$

Under the assumption that the $\left\{E^{\prime}(i)\right\}$ sequence is statistically independent, a new statistic $\mathrm{NF}_{m}$ is defined by

$$
\mathrm{NF}_{m}= \begin{cases}0, & m=1, \\ \frac{b_{m}-D\left(b_{m}\right)}{\sqrt{\operatorname{Var}\left(b_{m}\right)},} & 2 \leq m \leq n .\end{cases}
$$

Thus, the $\mathrm{NF}_{m}-F$ curve can be formed by all the $\mathrm{NF}_{k}$ data, and the $\mathrm{NB}_{k}-F$ curve can be formed by the inverse $\left\{E^{\prime}(i)\right\}$ sequence. Consequently, two $\mathrm{NF}_{k}$ and $\mathrm{NB}_{k}$ curves can intersect at the mutation point of the $E_{j, \text { norm }}-F_{j}$ curve, which is taken as a criterion to distinguish structural stressing state mutation.

\section{Experiment and Simulation of Concrete- Filled Stainless Steel and Steel Tubular Column}

3.1. Brief Introduction of Experiment. Wen et al. conducted experimental studies on the mechanical properties of the CFSSAST columns under axial and eccentric pressure [15]. The outer tube is stainless steel, and the inner tube is Q235 carbon steel, as shown in Figure 1.

In the axial compression test, the hollow ratio $\chi$ $\left(\chi=D_{i} /\left(D_{0}-2 t_{0}\right)\right.$ is the main variable parameter, and six short columns are made for experimental research. The sizes of specimen and material strength are shown in Table 1, in which only one end of specimens of class $a$ has an end plate, and both end of class $b$ has an end plate, where $f_{y 0}$ is the yield strength of stainless steel, $f_{y i}$ is the yield strength of carbon steel, and $f_{\mathrm{cu}}$ is the compressive strength of concrete.

Eighteen CFSSAST columns were made for the research of the eccentric compression test with the hollow ratio $\chi$ $\left(\chi=D_{i} /\left(D_{0}-2 t_{0}\right)\right)$, slenderness ratio $(\lambda=L / i)$, and eccentricity ratio $(e / r)$ as the main parameters. Table 2 shows the specific size and material strength of the specimens, and both ends of each specimen have an end plate.
3.2. Loading Device of Experiment. 500tYAW-5000 pressure tester is used for axial compression and eccentric compression test, as shown in Figure 2. Four displacement meters are used to measure the axial displacement $(\Delta)$ of the specimens in the axial compression test, and the longitudinal strain gauges and the transverse strain gauges are pasted in the middle of four longitudinal sections. In the eccentric compression test, the two ends of the specimen are, respectively, loaded by the knife edge hinge. Due to the difference of the section size, load eccentricity, and other parameters of the specimens, a loading plate with groove is added between the end of the specimen and the knife edge hinge, so as to evenly act the load on the specimen. In the eccentric compression test, five displacement meters are used to measure the axial displacement, the lateral deflection at the height of $1 / 4,1 / 2$, and $3 / 4$ column, and the longitudinal and transverse strain gauges are pasted in the middle of four longitudinal sections.

3.3. FEA Model of CFSSAST Column. Figure 3 shows the FEA model of CFSSAST columns built by Software ABAQUS. The concrete of CFSSAST short column and end plate were simulated by the solid element C3D8R, and the inner and outer steel tubes were simulated by the shell unit S4R. This paper adopted Rasmussen's stainless steel constitutive relationship model [21] and Han's carbon steel constitutive relationship model [22]. The constitutive relation of stainless steel is as follows:

$$
\varepsilon= \begin{cases}\frac{\sigma}{E_{0}}+0.002\left(\frac{\sigma}{\sigma_{0.2}}\right)^{n}, & \sigma \leq \sigma_{0.2}, \\ \frac{\sigma-\sigma_{0.2}}{E_{0.2}}+\varepsilon_{u}\left(\frac{\sigma-\sigma_{0.2}}{\sigma_{u}-\sigma_{0.2}}\right)^{m}+\varepsilon_{0.2}, & \sigma_{0.2}<\sigma,\end{cases}
$$

where $E_{0}$ is the initial modulus of elasticity of stainless steel; $E_{0.2}$ is the tangent modulus corresponding to the stressstrain curve when the residual strain is $0.2 \% ; \sigma_{0.2}$ is the corresponding stress when the residual strain is $0.2 \% ; \sigma_{u}$ is the ultimate stress of stainless steel; $\varepsilon_{u}$ is the ultimate strain of stainless steel.

The concrete adopted Guo tensile concrete constitutive relationship model [23] and Han compression concrete constitutive relationship models [22]. The constitutive relation of concrete in tensile zone is as follows:

$$
\frac{\sigma}{\sigma_{0}}=\left\{\begin{array}{cc}
1.2 \frac{\varepsilon}{\varepsilon_{p}}-0.2 \frac{\varepsilon^{0.6}}{\varepsilon_{p}}, & \frac{\varepsilon}{\varepsilon_{p}} \leq 1, \\
\frac{\left(\varepsilon / \varepsilon_{p}\right)}{0.3 \sigma_{p}^{2}\left(\left(\varepsilon / \varepsilon_{p}\right)-1\right)^{1.7}+\varepsilon / \varepsilon_{p}}, & \frac{\varepsilon}{\varepsilon_{p}}>1,
\end{array}\right.
$$

where $\sigma_{p}$ is the peak tensile stress of concrete and $\sigma_{p}=0.26 \times\left(1.25 f_{c}^{\prime}\right)^{2 / 3}, \varepsilon_{p}$ is the strain corresponding to the peak tensile stress, and $\varepsilon_{p}=43.1 \sigma_{p}$. 

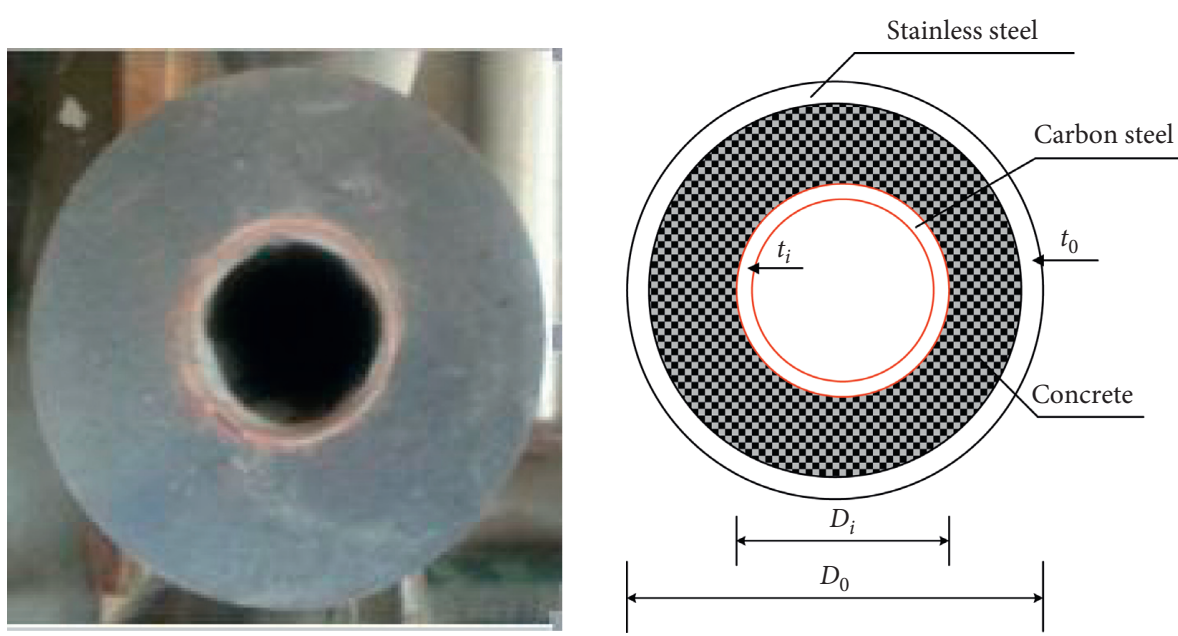

FIgURe 1: Section diagram of CFSSAST column.

TABLE 1: Size and strength of axial compression specimens.

\begin{tabular}{|c|c|c|c|c|c|c|c|}
\hline Specimen number & $D_{0} \times t_{0}(\mathrm{~mm} \times \mathrm{mm})$ & $D_{i} \times t(\mathrm{~mm} \times \mathrm{mm})$ & $L(\mathrm{~mm})$ & $\chi$ & $f_{y 0}(\mathrm{MPa})$ & $f_{y i}(\mathrm{MPa})$ & $f_{\mathrm{cu}}(\mathrm{MPa})$ \\
\hline $\mathrm{Z}-48-\mathrm{a}$ & $114 \times 2$ & $48 \times 1.6$ & 342 & 0.44 & 278.7 & 235 & 48 \\
\hline Z-48-b & $114 \times 2$ & $48 \times 1.6$ & 342 & 0.44 & 278.7 & 235 & 48 \\
\hline Z-76-a & $114 \times 2$ & $76 \times 1.6$ & 342 & 0.69 & 278.7 & 235 & 48 \\
\hline Z-76-b & $114 \times 2$ & $76 \times 1.6$ & 342 & 0.69 & 278.7 & 235 & 48 \\
\hline Z-89-a & $114 \times 2$ & $89 \times 1.6$ & 342 & 0.81 & 278.7 & 235 & 48 \\
\hline Z-89-b & $114 \times 2$ & $89 \times 1.6$ & 342 & 0.81 & 278.7 & 235 & 48 \\
\hline
\end{tabular}

TABLE 2: Size and strength of eccentric compression specimens.

\begin{tabular}{|c|c|c|c|c|c|c|}
\hline Specimen number & $D_{0} \times t_{0}(\mathrm{~mm} \times \mathrm{mm})$ & $D_{i} \times t_{i}(\mathrm{~mm} \times \mathrm{mm})$ & $L(\mathrm{~mm})$ & $f_{y 0}(\mathrm{MPa})$ & $f_{y i}(\mathrm{MPa})$ & $f_{\mathrm{cu}}(\mathrm{MPa})$ \\
\hline P800-50-4-a & $114 \times 2$ & $50 \times 1.2$ & 800 & 278.7 & 235 & 58 \\
\hline P800-50-4-b & $114 \times 2$ & $50 \times 1.2$ & 800 & 278.7 & 235 & 58 \\
\hline P800-76-14-a & $114 \times 2$ & $76 \times 1.6$ & 800 & 278.7 & 235 & 58 \\
\hline P800-76-14-b & $114 \times 2$ & $76 \times 1.6$ & 800 & 278.7 & 235 & 58 \\
\hline P800-89-45-a & $114 \times 2$ & $89 \times 1.6$ & 800 & 278.7 & 235 & 58 \\
\hline P800-89-45-b & $114 \times 2$ & $89 \times 1.6$ & 800 & 278.7 & 235 & 58 \\
\hline P1300-50-4-a & $114 \times 2$ & $50 \times 1.2$ & 1300 & 278.7 & 235 & 58 \\
\hline P1300-50-4-b & $114 \times 2$ & $50 \times 1.2$ & 1300 & 278.7 & 235 & 58 \\
\hline P1300-76-14-a & $114 \times 2$ & $76 \times 1.6$ & 1300 & 278.7 & 235 & 58 \\
\hline P1300-76-14-b & $114 \times 2$ & $76 \times 1.6$ & 1300 & 278.7 & 235 & 58 \\
\hline P1300-89-45-a & $114 \times 2$ & $89 \times 1.6$ & 1300 & 278.7 & 235 & 58 \\
\hline P1300-89-45-b & $114 \times 2$ & $89 \times 1.6$ & 1300 & 278.7 & 235 & 58 \\
\hline P1800-50-4-a & $114 \times 2$ & $50 \times 1.2$ & 1800 & 278.7 & 235 & 58 \\
\hline P1800-50-4-b & $114 \times 2$ & $50 \times 1.2$ & 1800 & 278.7 & 235 & 58 \\
\hline P1800-76-14-a & $114 \times 2$ & $76 \times 1.6$ & 1800 & 278.7 & 235 & 58 \\
\hline P1800-76-14-b & $114 \times 2$ & $76 \times 1.6$ & 1800 & 278.7 & 235 & 58 \\
\hline P1800-89-45-a & $114 \times 2$ & $89 \times 1.6$ & 1800 & 278.7 & 235 & 58 \\
\hline P1800-89-45-b & $114 \times 2$ & $89 \times 1.6$ & 1800 & 278.7 & 235 & 58 \\
\hline
\end{tabular}

\section{Stressing State Characteristics of CFSST Short Columns under Axial Compression}

4.1. Characteristics of $E_{j, \text { norm }}-F_{j}$ Curve. For the Z-48-b short column exampled here, the sum of GSED at each load $\left(F_{j}\right)$ can be normalized as $E_{j \text {,norm }}$ according to equations (1)-(3) and then the $E_{\mathrm{j} \text {,norm }}-F_{j}$ curve can be plotted. Furthermore, the loads $P(325 \mathrm{kN})$ and $U(609 \mathrm{kN})$ are two characteristic points distinguished by the $\mathrm{M}-\mathrm{K}$ criterion, which are elastoplastic critical load and failure load, respectively, as shown in Figure 4. Two mutation points divide the curve into three stages: (1) before load $P$, the curve is almost a horizontal straight line, indicating that the concrete could be in linear-elastic working state without cracks; (2) after load $P$, the curve increases nonlinearly, signifying that the short column enters the elastic-plastic stressing state stage until load $U$. At this time, the concrete exposed at the ends of the specimen begins to produce small and slowly 

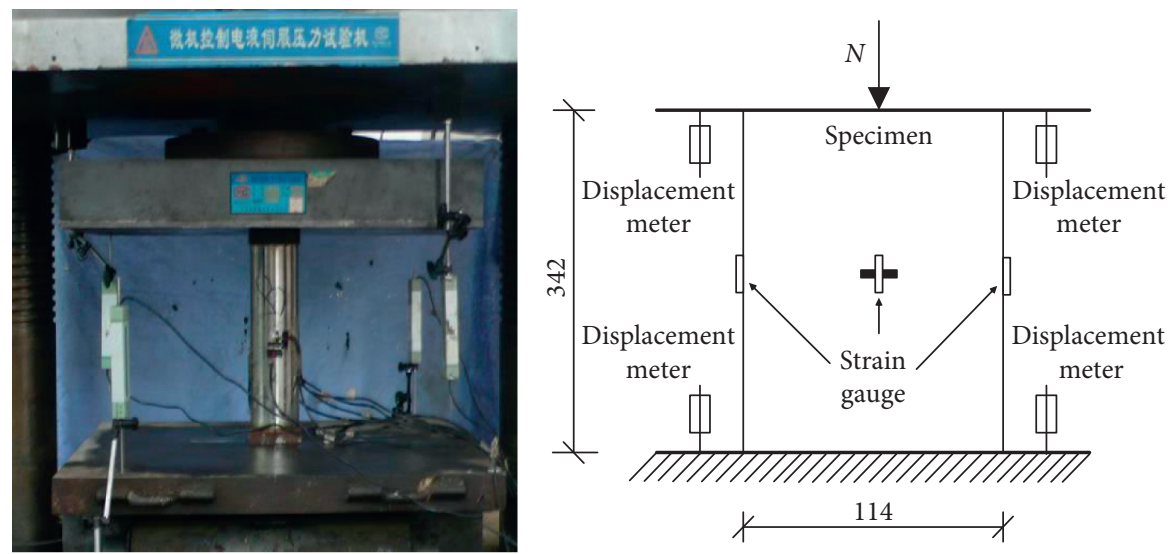

(a)
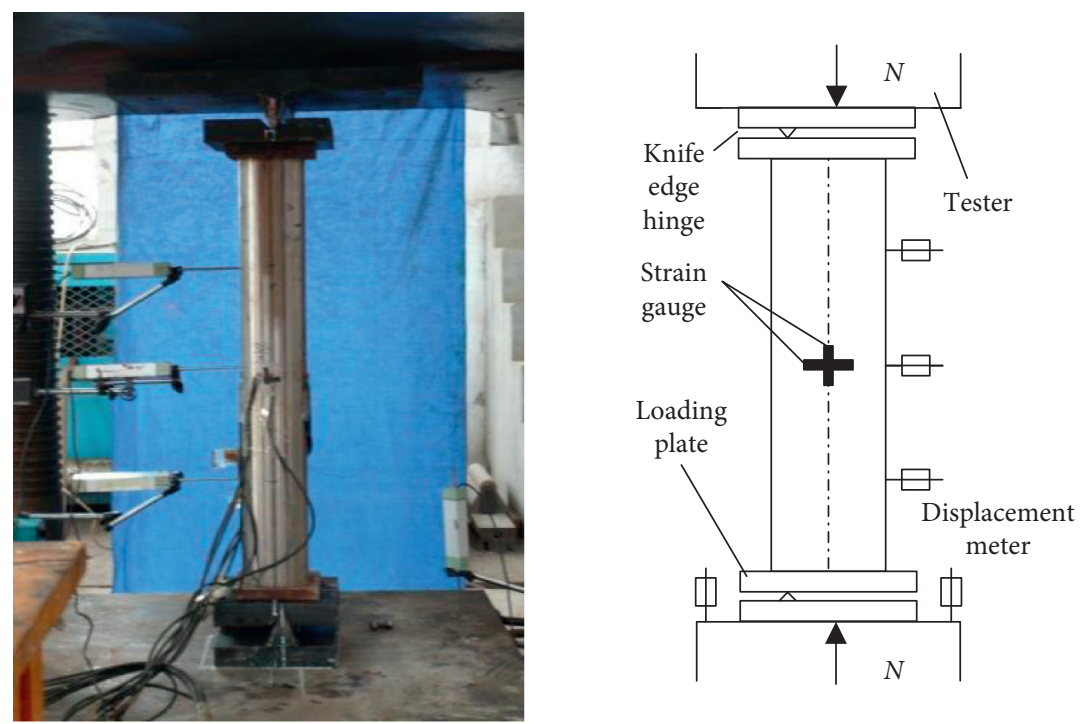

(b)

FIgURE 2: The loading device of (a) CFSSAST column under axial compression and (b) CFSSAST column under eccentric compression.

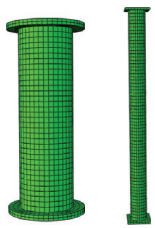

(a)

FIGURE 3: FEA model of short column (a) under axial compression and (b) under eccentric compression.

expanding cracks; (3) after load $U$, the curve rises sharply, implying that the short column enters the failure state in which the concrete produces more cracks, and the cracking level increases rapidly. Therefore, load $U$ is defined as the failure load of the short column, which conforms to the natural law of quantitative change to qualitative change. According to the natural law, it can be considered that the elastic working state and elastic-plastic working state of the short column before the failure load are a process of continuous "quantitative change." When a certain critical value

(i.e., failure load) is reached, there will be a qualitative change in the stressing state of the short column, and it can no longer bear the load stably.

To verify the general applicability of the failure load to all test short columns, the mutation of $E_{j, \text { norm }}-F_{j}$ curves of other short columns are also distinguished by $\mathrm{M}-\mathrm{K}$ criterion. The failure loads of short columns Z-48-a, Z-48-b, Z-76-a, Z-76-b, Z-89-a, and Z-89-b are $613 \mathrm{kN}, 609 \mathrm{kN}, 535 \mathrm{kN}$, $540 \mathrm{kN}, 462 \mathrm{kN}$, and $468 \mathrm{kN}$, respectively. Obviously, each curve has a mutation point from the stable stressing state to failure state, that is, failure load. By comparing the failure loads of short columns of class $a$ and $b$, it can be seen that the impact of end plates on the failure load is very small. Therefore, the failure load is deterministic, which reflects the general and common failure behavior of structural stressing state, and will be applied in the following analysis.

4.2. Verification of Simulated Data. In order to verify the accuracy of the simulated data, the ultimate loads and failure loads of the experimental columns and the models are 


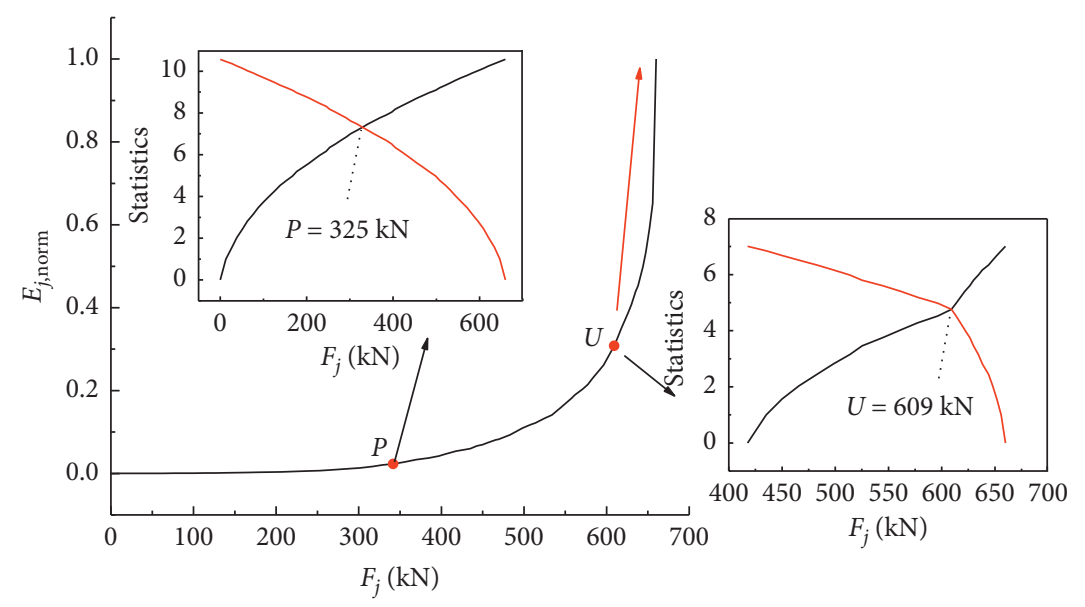

Figure $4: E_{j, \text { norm }}-F_{j}$ curve of Z-48-b.

compared, as shown in Table 3. The maximal absolute value of the error of simulated ultimate load and simulated failure load is $8.3 \%$ and $3.6 \%$, respectively, so the simulated data are accurate enough for further analysis.

It can be seen from Figure 5 that the simulation data are in agreement with the experiment data. At the same time, the displacement corresponding to the ultimate load in the simulation is smaller than that in the experiment, which may be the fact that the contact between the backing plate and the specimen as well as the loading device and the backing plate is not close. As for the comparison of other short columns not listed here, the results are also similar to those shown. Therefore, the simulated data are reliable and can be used for further analysis.

4.3. Stress Contour Maps Analysis of Axial Compression Model. The model Z-76 is taken as an example to analyze the stress change of the CFSSAST column during the loading process. The stress contour maps corresponding to the four characteristic loads are selected for analysis, and the sequence is: (1) point A: elastoplastic critical load; (2) point B: failure load; (3) point C: ultimate load; (4) point D: unloading load, as shown in Figure 6.

Figure 7 shows the longitudinal stress contour maps of the stainless steel tube. It can be seen that, at point $A$, the longitudinal stress at the end and the stress in the middle are $-206 \mathrm{MPa}$ and $-180 \mathrm{MPa}$, respectively. The stress at the end is 1.14 times that in the middle, and the stainless steel does not reach yield strength. At point $\mathrm{B}$, the end stress is $-284 \mathrm{MPa}$, the stress in the middle is $-249 \mathrm{MPa}$, and the ratio is still 1.14. When the load reaches ultimate load, the end stress and stress in the middle are $-301 \mathrm{MPa}$ and $-256 \mathrm{MPa}$, respectively, and the ratio is 1.1 . At point $\mathrm{D}$, the deformation of the stainless steel tube is obvious. The end stress and the stress in the middle are almost the same. After the failure load, the transverse deformation of the middle part increases significantly, and finally the middle part "bulges" outwards.

Figure 8 shows the longitudinal stress contour maps of the core concrete, and the end effect also exists at the initial stage of loading. At point A, the end stress and the stress in the middle of the outer side (the side close to the stainless steel tube) are $-40 \mathrm{MPa}$ and $-34 \mathrm{MPa}$, respectively, and the ratio of is 1.18. The stresses of the inner side (the side close to the carbon steel tube) are $-27 \mathrm{MPa}$ and $-34 \mathrm{MPa}$, respectively, with a ratio of 0.79 . For the end of the core concrete, the stress gradually decreases from the outer side to the inner side. For the midsection of the column, the stress at each point is almost the same. When the load reaches failure load, the ratio of outer side and inner side is 1.22 and 0.72 , respectively. After the failure load, the transverse deformation of the middle section of concrete increases rapidly.

As shown in Figure 9, due to the transverse supporting effect of concrete on carbon steel tube, the stressing state of carbon steel tube is different from that of stainless steel tube. At point $\mathrm{A}$, the stress at the end and the stress in middle of steel tube is $-187 \mathrm{MPa}$ and $-241 \mathrm{MPa}$, respectively, and the middle part of carbon steel tube has reached the yield strength. As the load continues, the end stress gradually increases, but it does not reach yield strength. Overall, it can be inferred that the carbon steel tube provides a lateral bracing force for the concrete, instead of directly bearing the vertical load.

4.4. Orthogonal Parameter Analysis of Axial Compression Model. In this paper, $L_{16}\left(4^{5}\right)$ orthogonal table is selected for parameter analysis, where 16 represents the number of models to be established; 4 means setting 4 levels for each parameter; 5 means that there are five parameters. The specific parameter settings of all 16 short column models are shown in Table 4 , and the range of ultimate load $\left(R_{u}\right)$ and the range of failure load $\left(R_{f}\right)$ are shown in Table 5 , where $N_{u}$ is the ultimate load of short column and $N_{f}$ is the failure load of short column.

According to Table 5, the range relation of each parameter is as follows: stainless steel strength $>$ nominal steel ratio $>$ concrete strength $>$ carbon steel strength $>$ hollow ratio. The results show that the strength of stainless steel and nominal steel ratio are the most important factors affecting the failure load and ultimate load of the short columns, followed by the strength of concrete, while the strength of carbon steel and the hollow ratio are the least. 
TABLE 3: Comparison of experimental data and simulated data.

\begin{tabular}{lcccccc}
\hline $\begin{array}{l}\text { Specimen } \\
\text { number }\end{array}$ & $\begin{array}{c}\text { Failure load of } \\
\text { experiment }(\mathrm{kN})\end{array}$ & $\begin{array}{c}\text { Simulated ultimate } \\
\text { load }(\mathrm{kN})\end{array}$ & $\begin{array}{c}\text { Error } \\
(\%)\end{array}$ & $\begin{array}{c}\text { Failure load of } \\
\text { experiment }(\mathrm{kN})\end{array}$ & $\begin{array}{c}\text { Simulated failure } \\
\text { load }(\mathrm{kN})\end{array}$ & $\begin{array}{c}\text { Error }(\%) \\
\text { Z-48-a }\end{array}$ \\
\hline 698 & 670 & 4.0 & 613 & 610 & -0.6 \\
Z-48-b & 660 & 670 & 1.5 & 609 & 610 & 0.1 \\
Z-48-a & 618 & 567 & 8.3 & 535 & 521 & -2.8 \\
Z-76-b & 578 & 567 & 1.9 & 540 & 421 & -3.6 \\
Z-89-a & 493 & 494 & 0.2 & 462 & 459 & -0.7 \\
Z-89-b & 520 & 494 & 5.0 & 468 & 459 \\
\hline
\end{tabular}

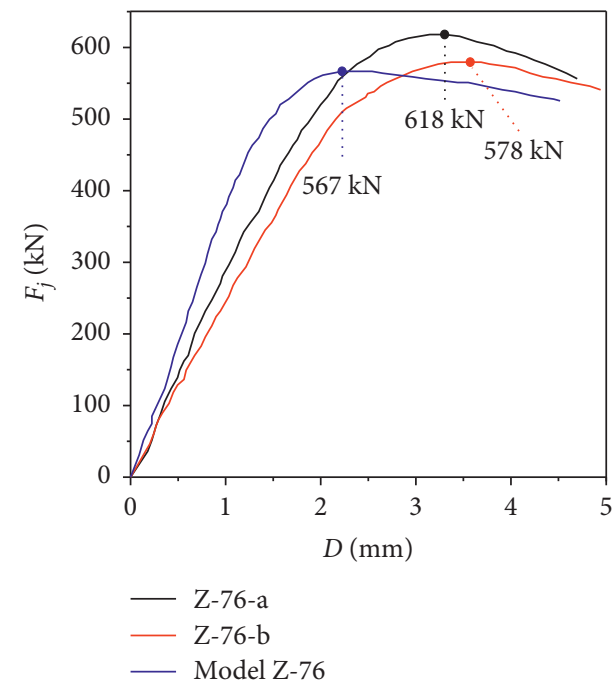

(a)

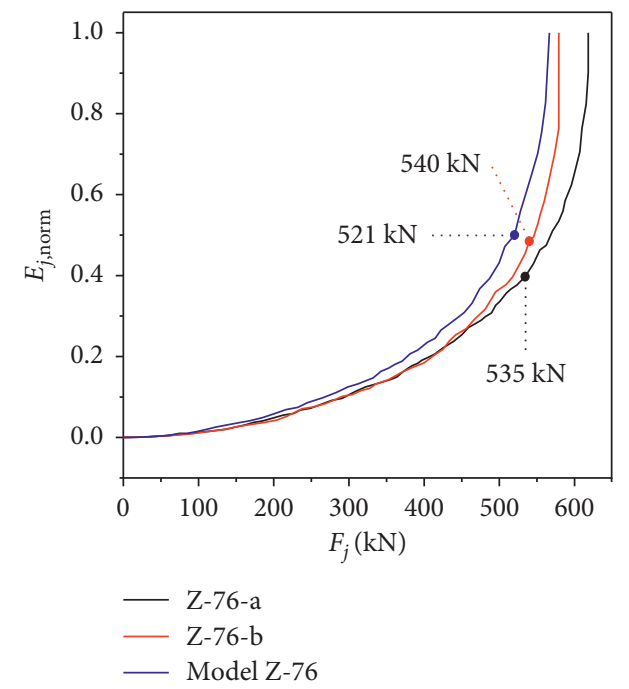

(b)

Figure 5: (a) $F_{j}-D$ curve of Model Z-76. (b) $E_{j, \text { norm }}-F_{j}$ curve of Model Z-76.

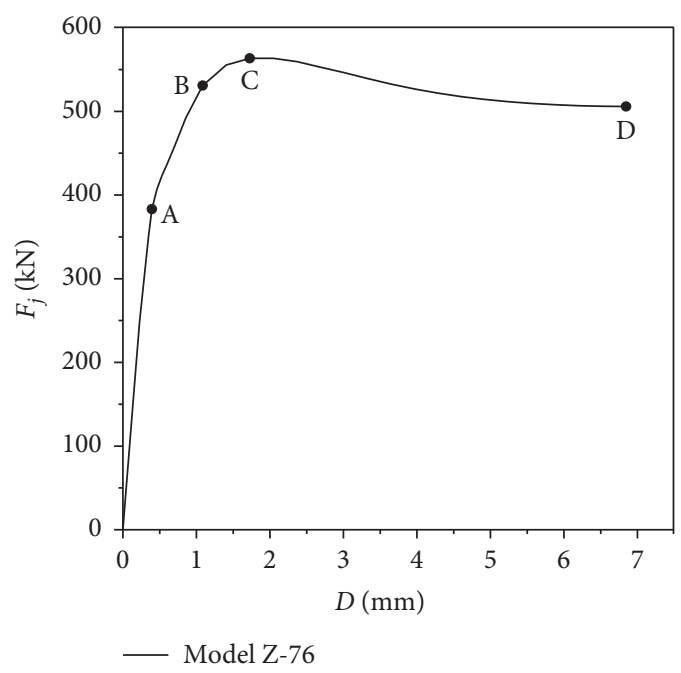

Figure 6: $F_{j}-D$ (displacement) curve of model z-76.

4.5. Single Variable Parameter Analysis. In this paper, five parameters (concrete strength, stainless steel yield strength, carbon steel strength, hollow ratio, and nominal steel ratio) are analyzed quantitatively by using the finite element model. At the same time, in order to compare the influence of different factors on the bearing capacity of short columns, this paper attempts to construct the parameter $K$, as shown in

$$
K=\frac{C_{1}}{C_{2}},
$$

where $\quad C_{1}=\left|U_{1}-U_{2}\right| / \min \left(U_{1}, U_{2}\right), \quad C_{2}=\left|X_{1}-X_{2}\right| \mid$ $\min \left(X_{1}, X_{2}\right), X_{1}$ and $X_{2}$ are the parameter levels, respectively, and $U_{1}$ and $U_{2}$ are the limit load and failure load corresponding to the two parameter levels, respectively.

4.6. Influence of Concrete Strength. It can be seen from Figure 10 that, with the increase of concrete strength, the ultimate load and failure load of the short column model increase. When the concrete strength increases from $40 \mathrm{MPa}$ to $80 \mathrm{MPa}$, increased by $100 \%\left(C_{2}\right.$ is 1$)$, the corresponding ultimate loads are $523.62 \mathrm{kN}, 559.29 \mathrm{kN}, 607.33 \mathrm{kN}$, $653.18 \mathrm{kN}$, and $703.21 \mathrm{kN}$, which are increased by $34.3 \%\left(C_{1}\right.$ is 0.343 ), and the value of $K$ is 0.3430 . The corresponding failure loads are $488.15 \mathrm{kN}, 535.17 \mathrm{kN}, 544.90 \mathrm{kN}, 610.50 \mathrm{kN}$, and $652.58 \mathrm{kN}$, which are increased by $33.68 \%\left(C_{1}\right.$ is 0.3368$)$, and $K$ is 0.3368 . In addition, with the concrete strength increases, the falling section after the ultimate load is more obvious, which shows that the ductility of the CFSSAST columns decreases with the increase of concrete strength. 


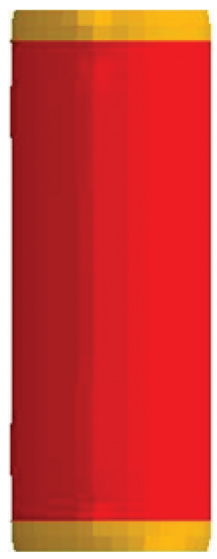

(a)

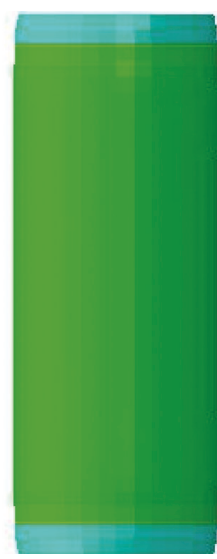

(b)

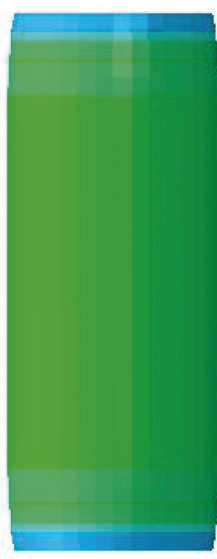

(c)

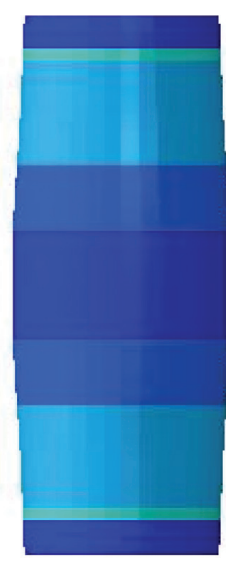

(d)

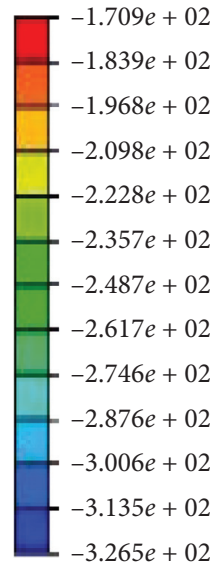

Figure 7: The longitudinal stress contour maps of the stainless steel tube. (a) Point A. (b) Point B. (c) Point C. (d) Point D.

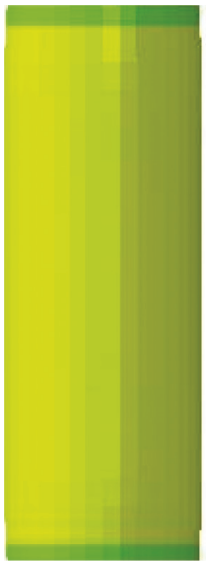

(a)

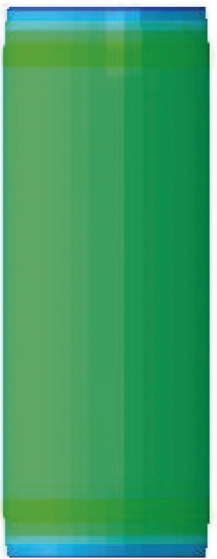

(b)

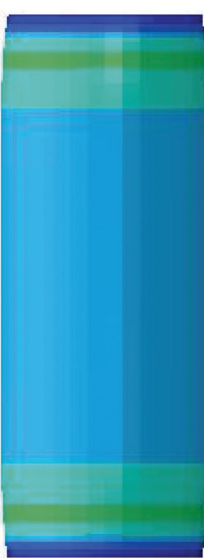

(c)

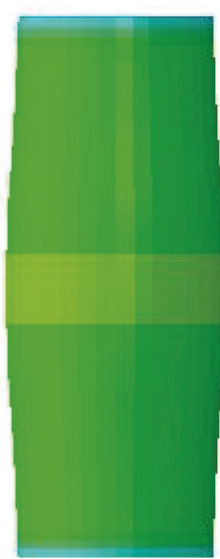

(d)

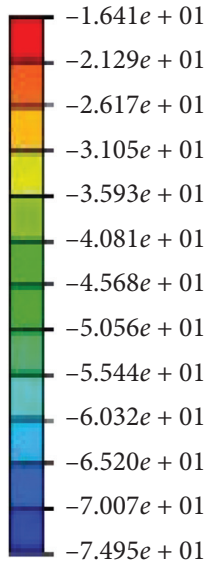

$-7.495 e+01$

Figure 8: The longitudinal stress contour maps of the core concrete. (a) Point A. (b) Point B. (c) Point C. (d) Point D.

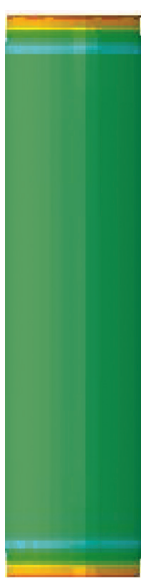

(a)

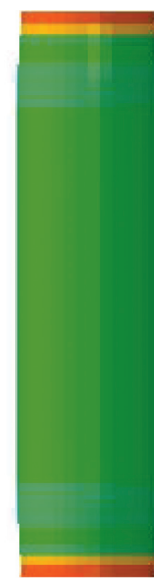

(b)

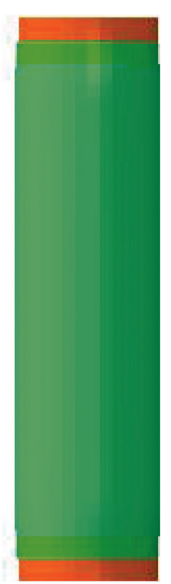

(c)

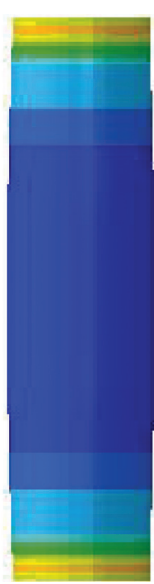

(d)

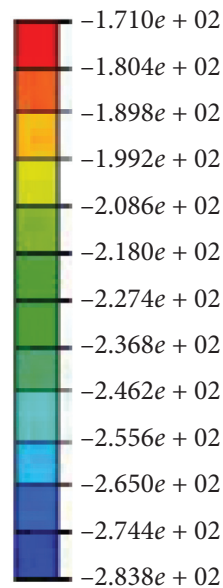

$-2.838 e+02$

Figure 9: The longitudinal stress contour maps of the carbon steel tube. (a) Point A. (b) Point B. (c) Point C. (d) Point D. 
TABLE 4: Model parameter level settings.

\begin{tabular}{|c|c|c|c|c|c|c|c|}
\hline Specimen number & $D_{i}(\mathrm{~mm})$ & $t_{0}(\mathrm{~mm})$ & $f_{\mathrm{cu}}(\mathrm{MPa})$ & $f_{y o}(\mathrm{MPa})$ & $f_{y i}(\mathrm{MPa})$ & $N_{u}(\mathrm{kN})$ & $N_{f}(\mathrm{kN})$ \\
\hline 1 & 40 & 1.2 & 40 & 275 & 235 & 514 & 481 \\
\hline 2 & 40 & 1.6 & 50 & 335 & 300 & 600 & 518 \\
\hline 3 & 40 & 2.0 & 60 & 412 & 345 & 911 & 821 \\
\hline 4 & 40 & 2.4 & 70 & 496 & 400 & 1163 & 1043 \\
\hline 5 & 50 & 2.4 & 40 & 335 & 345 & 804 & 761 \\
\hline 6 & 50 & 2.0 & 50 & 275 & 400 & 738 & 651 \\
\hline 7 & 50 & 1.6 & 60 & 496 & 235 & 929 & 793 \\
\hline 8 & 50 & 1.2 & 70 & 412 & 300 & 790 & 709 \\
\hline 9 & 60 & 1.6 & 40 & 412 & 400 & 740 & 666 \\
\hline 10 & 60 & 1.2 & 50 & 496 & 345 & 754 & 673 \\
\hline 11 & 60 & 2.4 & 60 & 275 & 300 & 779 & 681 \\
\hline 12 & 60 & 2.0 & 335 & 235 & 235 & 837 & 763 \\
\hline 13 & 70 & 2.0 & 40 & 496 & 300 & 908 & 811 \\
\hline 14 & 70 & 2.4 & 50 & 412 & 235 & 801 & 705 \\
\hline 15 & 70 & 1.2 & 60 & 335 & 400 & 670 & 571 \\
\hline 16 & 70 & 1.6 & 70 & 275 & 345 & 700 & 601 \\
\hline
\end{tabular}

TABLE 5: The calculation results of range.

\begin{tabular}{llclll}
\hline & $D_{i}$ & $t_{0}$ & $f_{\text {cu }}$ & $f_{\text {yo }}$ & \\
\hline$R_{u}$ & 46 & 205 & 149 & 256 & 59 \\
$R_{f}$ & 57 & 189 & 142 & 226 & 47 \\
\hline
\end{tabular}

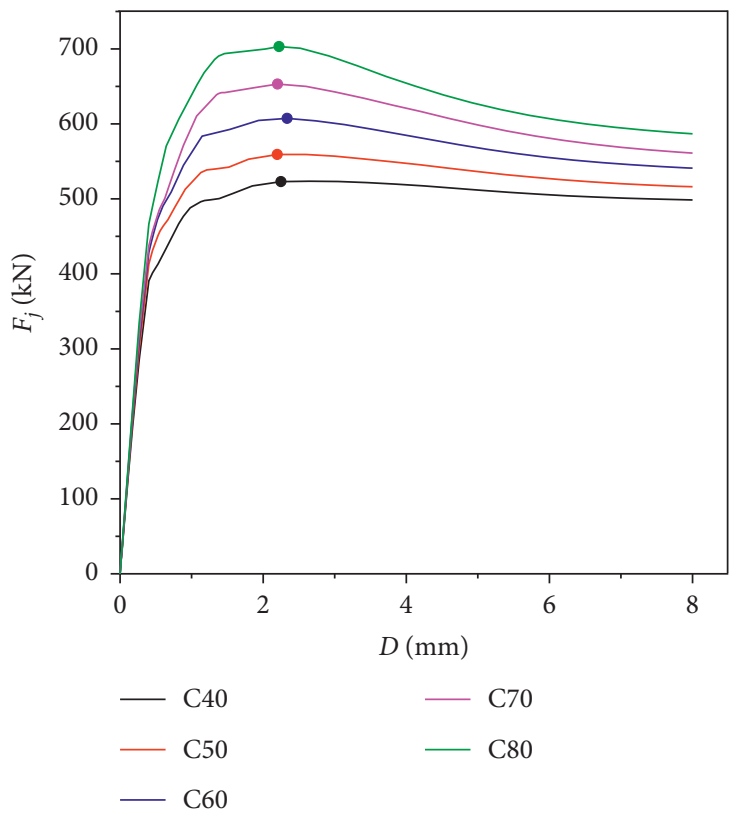

(a)

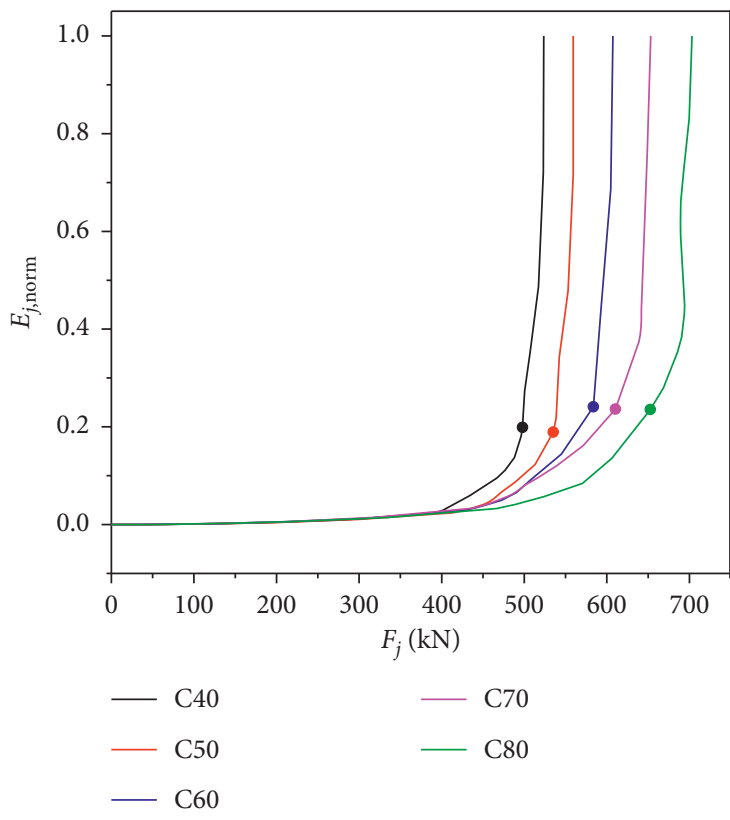

(b)

FIgURE 10: (a) $F_{j}-D$ curves of different concrete strength. (b) $E_{j, \text { norm }}-F_{j}$ curves of different concrete strength.

4.6.1. Effect of Yield Strength of Stainless Steel. As shown in Figure 11, the strength of stainless steel increases from $275 \mathrm{MPa}$ to $496 \mathrm{MPa}$, increased by $83.4 \%$, the corresponding ultimate load increases by $39.71 \%$ and $K$ is 0.4762 . The failure load increases by $40.48 \%$ and $K$ is 0.4854 . It can be seen from Figure 11 that the ductility of short columns is less affected by stainless steel strength.
4.6.2. Effect of Nominal Steel Ratio. The steel ratio increases from 0.0435 to 0.0898 (the nominal steel ratio is achieved by changing the thickness of stainless steel tube), which increases by $106.44 \%$, and the corresponding limit load increases by $25.67 \%$ and $K$ value is 0.2421 . The failure load increases by $27.45 \%$ and $K$ value is 0.2590 . At the same time, Figure 12(a) shows that, with the increase of nominal steel ratio, the falling stage of $F_{j}-D$ (displacement) curve becomes 


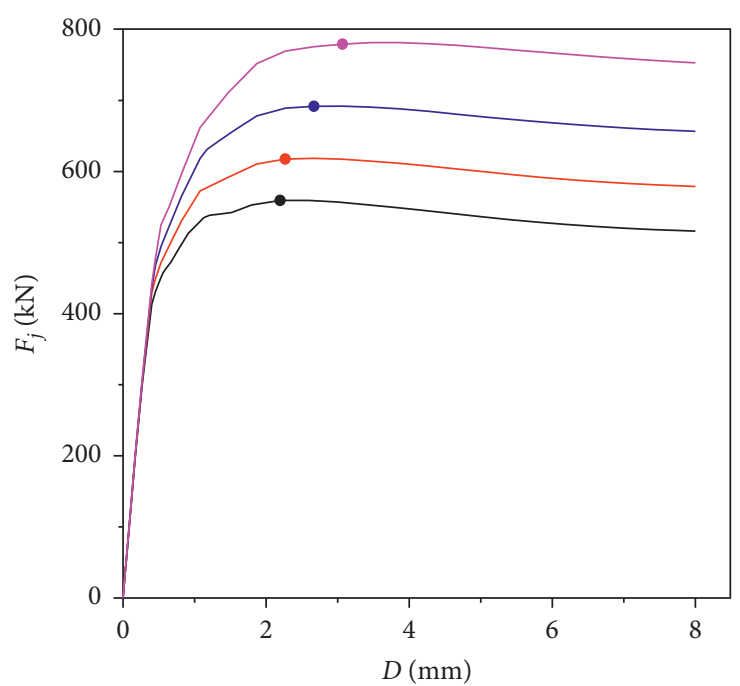

Yield strength of stainless steel:

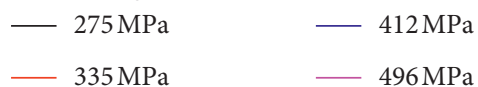

(a)

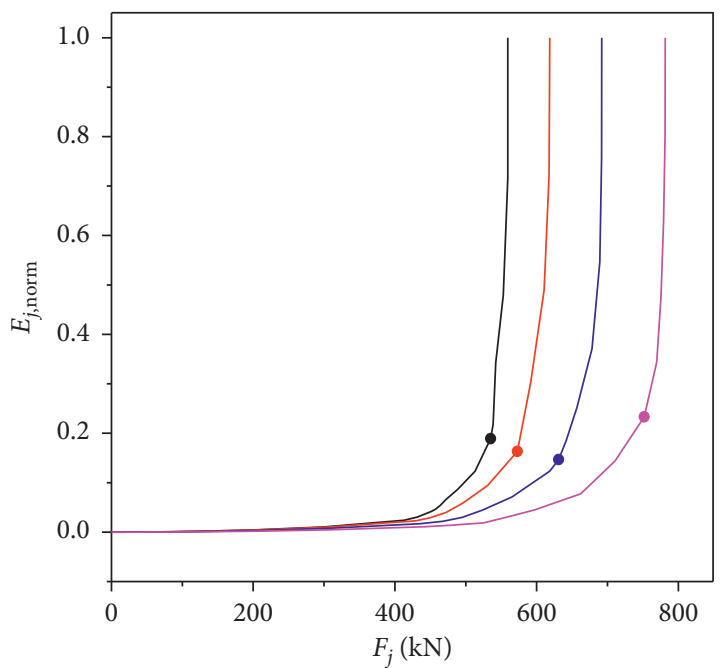

Yield strength of stainless steel:

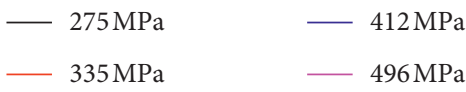

(b)

Figure 11: (a) $F_{j}-D$ curves of different yield strength of stainless steel. (b) $E_{j, \text { norm }}-F_{j}$ curves of different yield strength of stainless steel.

more and more gentle, indicating that the increase of nominal steel ratio can improve the ductility of short columns.

\subsection{Equation of the CFSSAST Columns under Axial Compression.} At present, there are few researches on the equation of bearing capacity of the CFSSAST columns, and the equation of failure load is not involved. This paper attempts to fit the equation of ultimate load and failure load on the basis of parameter analysis and relevant research.

4.7.1. Equation of Ultimate Load. Huang Hong put forward the equations of the bearing capacity of the CFDST columns $\left(N_{u}\right)$ through a lot of parameter analyses [1]. The equation is composed of two parts: the compound bearing capacity of the outer steel tube and the concrete $\left(N_{\text {osc }}, u\right)$, and the bearing capacity of the inner steel tube $\left(N_{i, u}\right)$. The interaction between the steel tube and the concrete is considered in $N_{\text {osc }}, u$ and the equation is shown as follows:

$$
\left\{\begin{array}{l}
N_{u}=N_{\mathrm{osc}, u}+N_{i, u}, \\
N_{\mathrm{osc}, u}=f_{\mathrm{scy}} A_{\mathrm{sco}}, \\
N_{i, u}=f_{y i} A_{s i}, \\
f_{\mathrm{scy}}=C_{1} \chi^{2} f_{y o}+C_{2}(1.14+1.02 \xi) f_{\mathrm{ck}}, \\
C_{1}=\frac{\alpha}{(1+\alpha)}, \\
C_{2}=\frac{(1+\alpha)}{(1+\alpha)}, \\
A_{\mathrm{sco}}=A_{s o}+A_{c},
\end{array}\right.
$$

where $f_{\text {scy }}$ is the compound strength of outer steel tube and concrete; $A_{\text {sco }}$ is the sum of cross sectional area of outer steel tube and concrete; $f_{y i}, f_{y o}$ and $f_{\text {ck }}$ are the yield strength of inner steel tube, yield strength of outer steel tube, and compressive strength of concrete, respectively; $A_{s i}, A_{s o}$ and $A_{c}$ are the cross sectional areas of inner steel tube, outer steel tube, and concrete, respectively; $\mathrm{a}$ and $\mathrm{a}_{n}$ are the steel ratio and nominal steel ratio, respectively; $\chi$ is the slenderness ratio; $\xi$ is constraint effect coefficient, $\xi=\mathrm{a}_{n} \times\left(f_{y o} / f_{\mathrm{ck}}\right)$. Equation (11) is applicable to the calculation of the ultimate bearing capacity of the CFDST columns. However, the outer steel tube of the CFSSAST column in this paper is made of stainless steel, so it is assumed to fit the equation of the ultimate bearing capacity $\left(N_{u, z}\right)$ on the basis of equation (11). Because the inner steel tube of CFSSAST column is still the carbon steel, the equation of $N_{i, u}$ is still the same. And the equation only needs to improve $N_{\text {osc }, u}$ (that is to fit some calculating coefficients of $\left.f_{\text {scy }}\right)$. After analysis, the equation is as follows:

$$
\left\{\begin{array}{l}
N_{u, z}=N_{\mathrm{osc}, z}+N_{i, u}, \\
N_{\mathrm{osc}, z}=f_{\mathrm{scy}} A_{\mathrm{sco}}, \\
N_{i, u}=f_{y i} A_{s i}, \\
f_{\mathrm{scy}}=C_{1} \chi^{2} f_{y o}+C_{2}\left(3.01 \xi^{3}-6.31 \xi^{2}+5.78 \xi+0.31\right) f_{\mathrm{ck}} \\
C_{1}=\frac{\alpha}{(1+\alpha)} \\
C_{2}=\frac{(1+\alpha)}{(1+\alpha)} \\
A_{\mathrm{sco}}=A_{s o}+A_{c} .
\end{array}\right.
$$




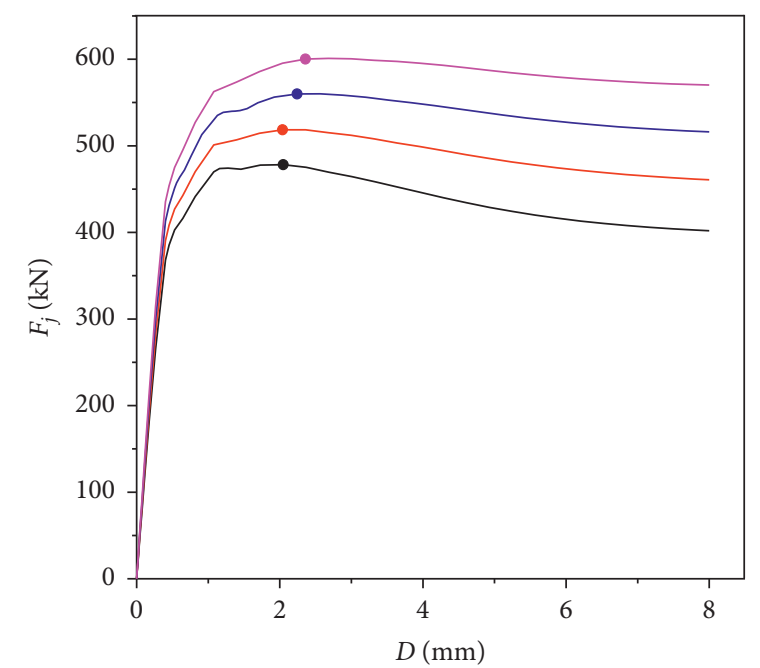

Nominal steel ratio:

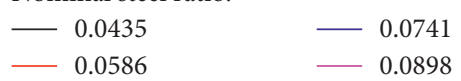

(a)

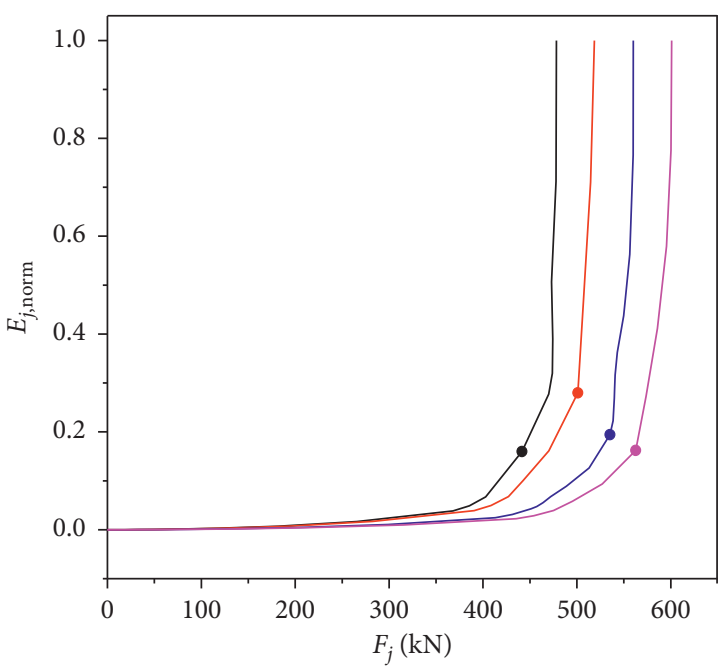

Nominal steel ratio:

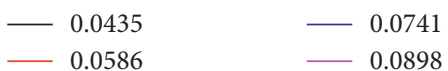

(b)

Figure 12: (a) $F_{j}-D$ curves of different nominal steel ratio, (b) $E_{j, \text { norm }}-F_{j}$ curves of different nominal steel ratio.

According to the newly fitted equations, the ultimate loads of 137 different short columns (including 6 test short columns and 131 simulated short columns) are calculated, among which 97 (accounting for $70.8 \%$ ) short columns have errors within $3 \%$, with an average error of $0.89 \%$ and a standard deviation of $3.45 \%$. The accuracy of the equation is enough for analysis.

4.7.2. Equation of Failure Load. The equation for calculating the failure load is still in the form of ultimate load $\left(N_{f}\right)$; that is, the equation is composed of two parts. One part is the compound failure load $\left(N_{\text {osc }, f}\right)$ of the outer steel tube and concrete (taking into account the constraint effect of steel tube on concrete), and the other part is the failure load of the inner steel tube $\left(N_{i, f}\right)$. The fitting equation is as follows:

$$
\left\{\begin{array}{l}
N_{f}=N_{\mathrm{osc}, f}+N_{i, f}, \\
N_{\mathrm{osc}, f}=f_{\mathrm{scy}, f} A_{\mathrm{sco}}, \\
N_{i, f}=0.93 A_{s i} f_{y i}, \\
f_{\mathrm{scy}, f}=C_{1} \chi^{2} f_{y o}+C_{2}\left(1.97 \xi^{3}-4.16 \xi^{2}+4.33 \xi+0.45\right) f_{\mathrm{ck}} .
\end{array}\right.
$$

The failure loads of 137 different specimens are calculated by the equation. Among them, the 89 specimens have errors within $3 \%$, accounting for $65.0 \%$, the average error is $0.07 \%$, and the standard deviation is $3.05 \%$. These data prove the accuracy of the equation.

\section{Stressing State Characteristics of CFSST Short Columns under Eccentric Compression}

5.1. Characteristics of $E_{j, n o r m}-F_{j}$ Curve. Take the model P1300-76-14 (eccentric compression column) as an example; the $E_{j \text {,norm }}-F_{j}$ curve can be plotted with the experimental data, as shown in Figure 13. Similar to short columns under axial compression, two characteristic loads of $P$ and $U$ are obtained by $\mathrm{M}-\mathrm{K}$ criterion. The columns under eccentric compression are divided into three stages during loading process: elastic working state (before load $P$ ), elastic-plastic working state (between load $P$ and load $U$ ), and failure state (after load $U$ ).

5.2. Verification of Simulated Data. To verify the rationality of the FE model, the errors of the simulated ultimate loads are obtained by comparing the simulated results with the experimental results, as shown in Table 6. The errors of the model are all within $10 \%$, and the average error is $-1.08 \%$. In a word, the accuracy of the model meets the requirements for further analysis.

5.3. Transverse Strain Analysis of Different Sections. In order to further explain the mutations of the stressing state of the eccentric compression columns, several cross sections are selected for analysis. They are section A (in the middle of column), section $\mathrm{D}$ (at the end), and sections $B$ and $C$ ( $B$ and $C$ are sections of trisection of sections $A$ and $D$ ), where section $B$ is closer to section $A$. It can be seen from Figure 14 that, before load $P$, the curve of each section changes linearly and the strain differences of different sections are very small. From load $P$ onwards, the curves tend to increase in a nonlinear way and begin to diverge; that is, the growth rate of section $\mathrm{D}$ starts to be smaller than that of the other three sections. After load $U$, the curve of each section increases rapidly, and the growth rate of section $A$ is larger than that of other sections. 


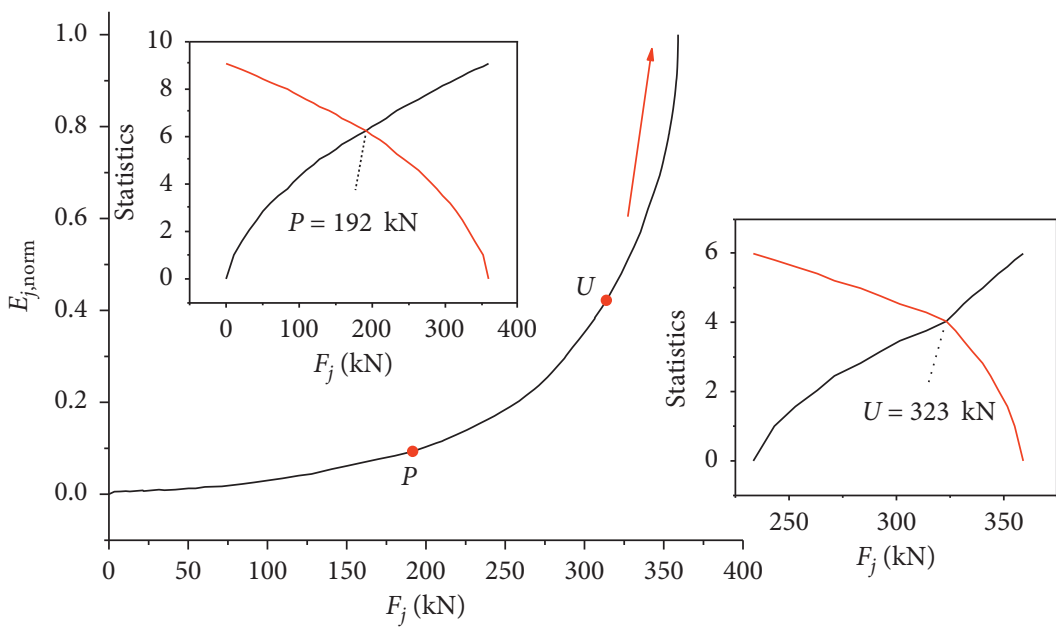

FIGURE 13: $E_{j, \text { norm }}-F_{j}$ curve of P1300-76-14.

TABLE 6: Comparison of experimental data and simulated data.

\begin{tabular}{lccc}
\hline Specimen number & Mean value of experimental ultimate load $(\mathrm{kN})$ & Mean value of simulated ultimate load $(\mathrm{kN})$ & Error $(\%)$ \\
\hline P800-50-4 & 653 & 669.93 & 2.59 \\
P800-76-14 & 436 & 406.41 & -6.79 \\
P800-89-45 & 200 & 218.83 & 9.42 \\
P1300-50-4 & 556 & 554.34 & -0.30 \\
P1300-76-14 & 380 & 358.98 & -5.53 \\
P1300-89-45 & 201 & 193.98 & -3.49 \\
P1800-50-4 & 492 & 487.19 & -0.98 \\
P1800-76-14 & 300 & 305.07 & 1.69 \\
P1800-89-45 & 181 & 169.49 & -6.36 \\
\hline
\end{tabular}

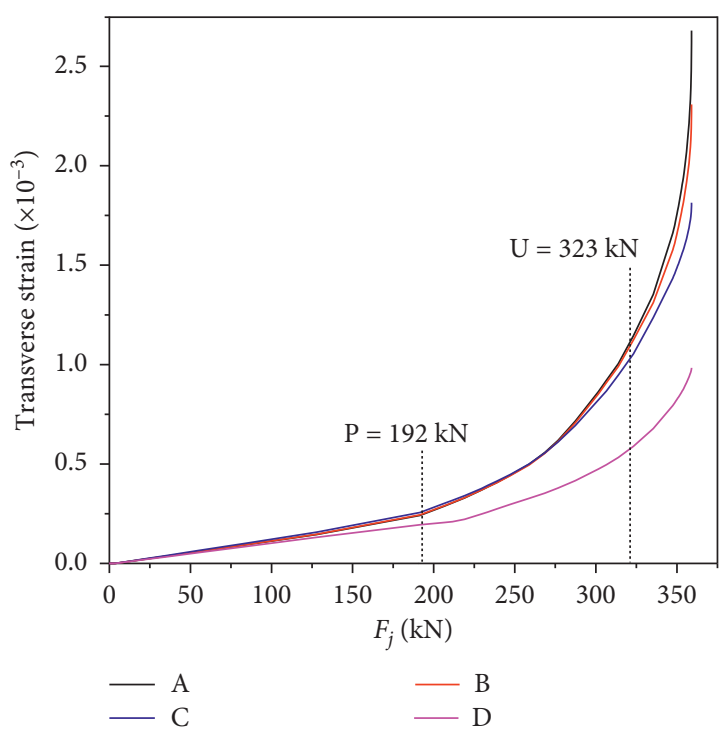

(a)

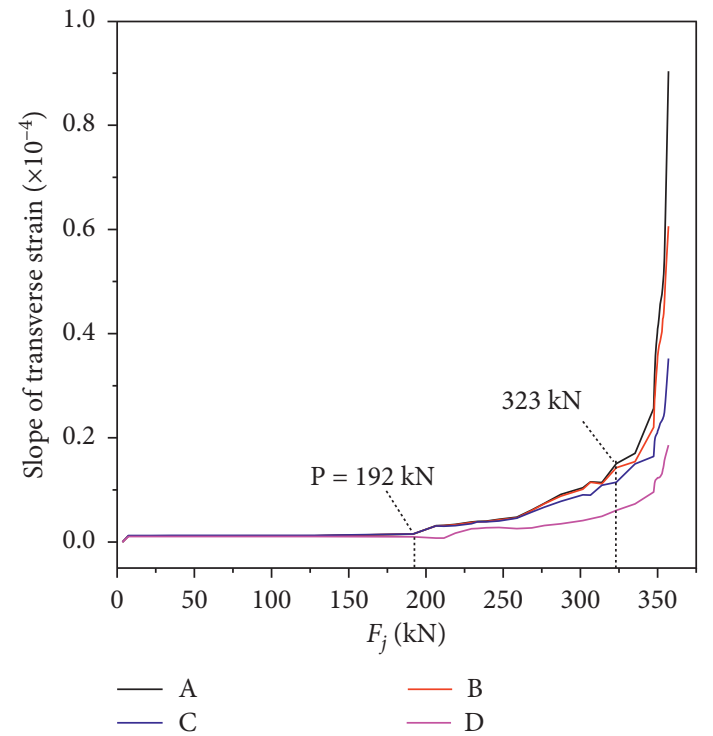

(b)

FIgURE 14: (a) Transverse strain $-F_{j}$ curves of different sections. (b) Slope of transverse strain $-F_{j}$ curves of different sections.

5.4. Stress Contour Maps Analysis of Eccentric Compression Model. Similar to the axial compression column, model P1300-76-14 is selected for analyzing the stress change of eccentric compression column during the whole loading process. The stress contour maps corresponding to four representative loads are selected for analysis. The four loads are (1) point A: elastoplastic critical load, (2) point B: failure load, (3) point C: ultimate load, and (4) point D: load 
corresponding to $30 \%$ reduction of bearing capacity, respectively (Figure 15).

Figure 16 shows the longitudinal stress contour maps of the stainless steel tube at four points. The side where the eccentric load is located is defined as the inner side, while the opposite side is defined as the outer side. At point A, the longitudinal stress of the inner side of the middle section is $-145 \mathrm{MPa}$, and the outer side of the middle section is $-17 \mathrm{MPa}$, which do not reach the yield strength of stainless steel. At point $\mathrm{C}$, the stress of inner side gradually decreases from the middle to both ends, and the maximum stress (in the middle section) and the minimum stress (at the end section) are $-283 \mathrm{MPa}$ and $-227 \mathrm{MPa}$, respectively (the stainless steel tube reaches yield strength). The stress of outer side is tensile stress, and the stress distribution is similar to that of the inner side. At the same time, the maximum stress (in the middle section) and the minimum stress (at the end section) are $185 \mathrm{Mpa}$ and $4 \mathrm{MPa}$, respectively. In the falling stage of load, the structural deformation is more and more large, and the stress on both sides tends to concentrate on the middle section.

The stress of concrete at four points is different from that of stainless steel tube, as shown in Figure 17. When the load reaches elastoplastic critical load, the compressive stress of the middle section is the largest, and the inner side and the outer side are $-29 \mathrm{MPa}$ and $-7 \mathrm{MPa}$, respectively. At point $\mathrm{B}$, the stresses of inner side and outer side of the middle section are $-50 \mathrm{MPa}$ and $-0.6 \mathrm{MPa}$, respectively, and the tensile stress is about to appear on the outer side. When the load reaches the ultimate load, the stress in most middle areas of the inner side is $-62 \mathrm{MPa}$, and the stress at both ends is $-48 \mathrm{MPa}$. The maximum tensile stress of the outer side is $3.7 \mathrm{MPa}$. As the load continues, the deformation of the structure becomes larger, and the compressive stress of inner side tends to concentrate on the middle section, and the maximum tensile stress of outer side gradually approaches the end section.

5.5. Single Variable Parameter Analysis. According to the principle of single variable, the influences of 7 factors on the bearing capacity of eccentrically loaded columns are analyzed, including nominal steel ratio, slenderness ratio, hollow ratio, concrete strength, stainless steel strength, carbon steel strength, and load eccentricity. In order to ensure the reliability of simulated results, the level of each parameter should be maintained at the experimental level.

5.5.1. Influence of Nominal Steel Ratio. Figures 18(a) and 18 (b) are the $F_{j}$ (load) - MPD (middle point deflection of the columns) curves and $E_{j, \text { norm }}-F_{j}$ characteristic curves of eccentrically compressed columns, respectively. The points marked on the deflection curves are the ultimate loads, and the points marked on the characteristic curves are the failure loads (these points are also used for the

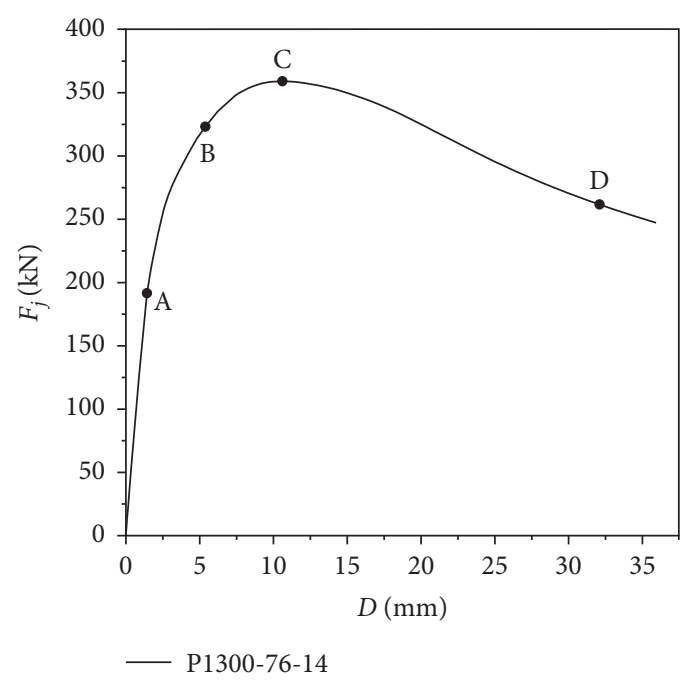

Figure 15: $F_{j}-D$ (displace) curves of the model P1300-76-14.

following parameter analysis). The nominal steel ratio increases from 0.0435 to 0.0898 , increased by $106.4 \%$, and the corresponding ultimate loads are $279.98 \mathrm{kN}$, $309.68 \mathrm{kN}, 340.13 \mathrm{kN}$, and $365.69 \mathrm{kN}$, respectively, increased by $30.61 \%$ and the value of $K$ is 0.2877 . The corresponding failure loads are $267.08 \mathrm{kN}, 291.76 \mathrm{kN}$, $313.39 \mathrm{kN}$, and $340.93 \mathrm{kN}$, increased by $27.65 \%$, and $K$ is 0.2599 . Figure 18 (a) shows that although the ultimate load of eccentric compression column increases, the deflection in the column corresponding to the ultimate load keeps the same, and the trend of the falling stage after the ultimate load also remains the same, indicating that the change of nominal steel ratio has few effects on the ductility of the eccentric compression column.

5.5.2. Influence of the Slenderness Ratio. As shown in Figure 19, the ultimate load and failure load of the eccentric compression column will decrease obviously with the rise of slenderness ratio. The slenderness ratio increases by $150.0 \%$ (from 25.97 to 64.92), and the corresponding ultimate load decreases by $65.40 \%$, and $K$ is 0.4360 . The corresponding failure load reduces by $75.86 \%$ and $K$ is 0.5057 . The deflection of the column corresponding to the ultimate load also improves with the slenderness ratio increasing, and the decline stage after the ultimate load tends to be gentle, which shows that, in a certain range, the ductility of the eccentric compression column increases with the rise of slenderness ratio.

5.5.3. Influence of Hollow Ratio. The hollow ratio increases by $199.6 \%$ (from 0.273 to 0.818 ), and the corresponding ultimate load decreases by $28.56 \%$ and the $K$ is 0.1431 . The corresponding failure load reduces by $27.25 \%$ and $K$ is 0.1365 . With the increase of hollow ratio, the decrease of ultimate load becomes more obvious, and the deflection of the column corresponding to ultimate load is smaller. The difference of ultimate load with hollow ratio of 0.273 and 


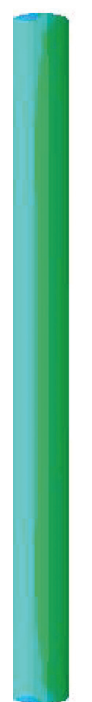

(a)

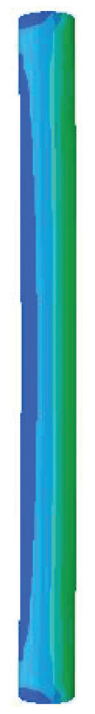

(b)

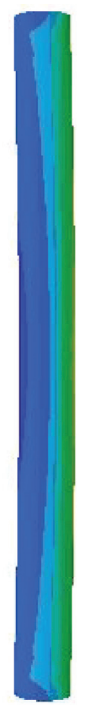

(c)

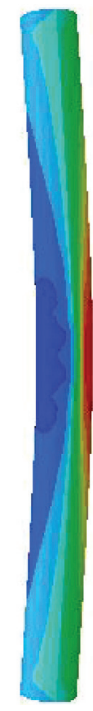

(d)

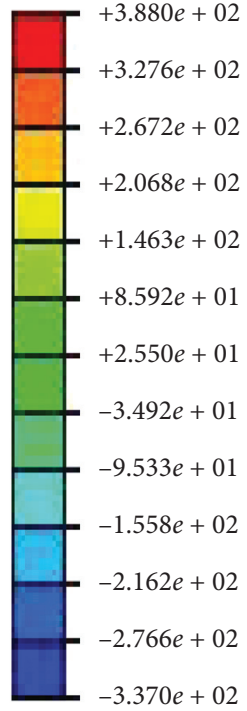

Figure 16: The longitudinal stress contour maps of the stainless steel tube. (a) Point A. (b) Point B. (c) Point C. (d) Point D.

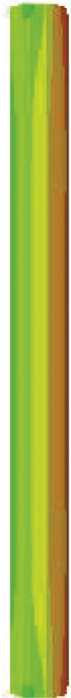

(a)

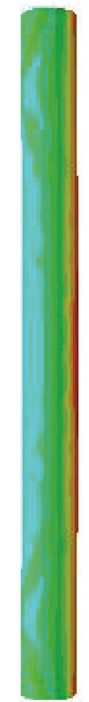

(b)

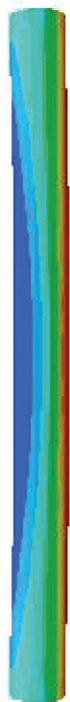

(c)
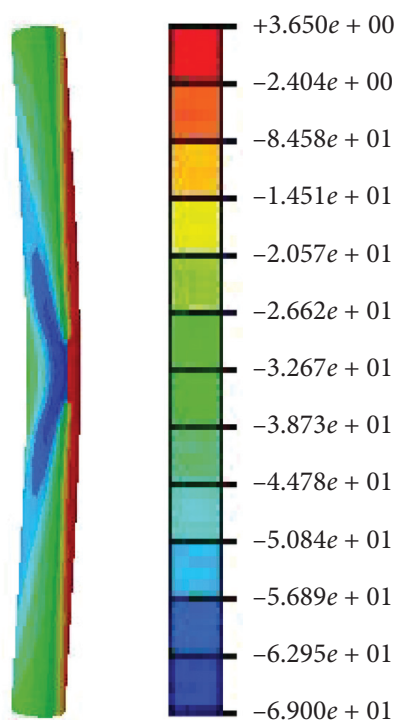

(d)

Figure 17: The longitudinal stress contour maps of the concrete. (a) Point A. (b) Point B. (c) Point C. (d) Point D.

0.455 is within $5 \%$, and the curves almost coincide. It may be the fact that when the hollow ratio is small to a certain critical value, it is equivalent to the solid stainless steel tubular concrete column, so the curves of the two columns of different hollow ratio are almost the same. Meanwhile, the falling stages of several curves are nearly parallel, which shows that the change of hollow ratio has few effects on the ductility of eccentric compression columns (Figure 20).

The analysis of other parameters is the same as above, and the comprehensive comparison of the $R$ (range) and $K$ of each parameter shows that the load eccentricity and slenderness ratio have the most significant impact on the bearing capacity of eccentrically compressed columns, followed by the stainless steel strength, nominal steel ratio, and concrete strength, while the hollow ratio and carbon steel strength have the least impact on the bearing capacity.

\section{Equation of the CFSSAST Columns under Eccentric Compression}

6.1. Equation for Predicting Ultimate Load. Based on the experiment and a large number of simulation parameter analyses, Tao et al. [1] found that the CFDST columns under eccentric compression meet the following equations: 

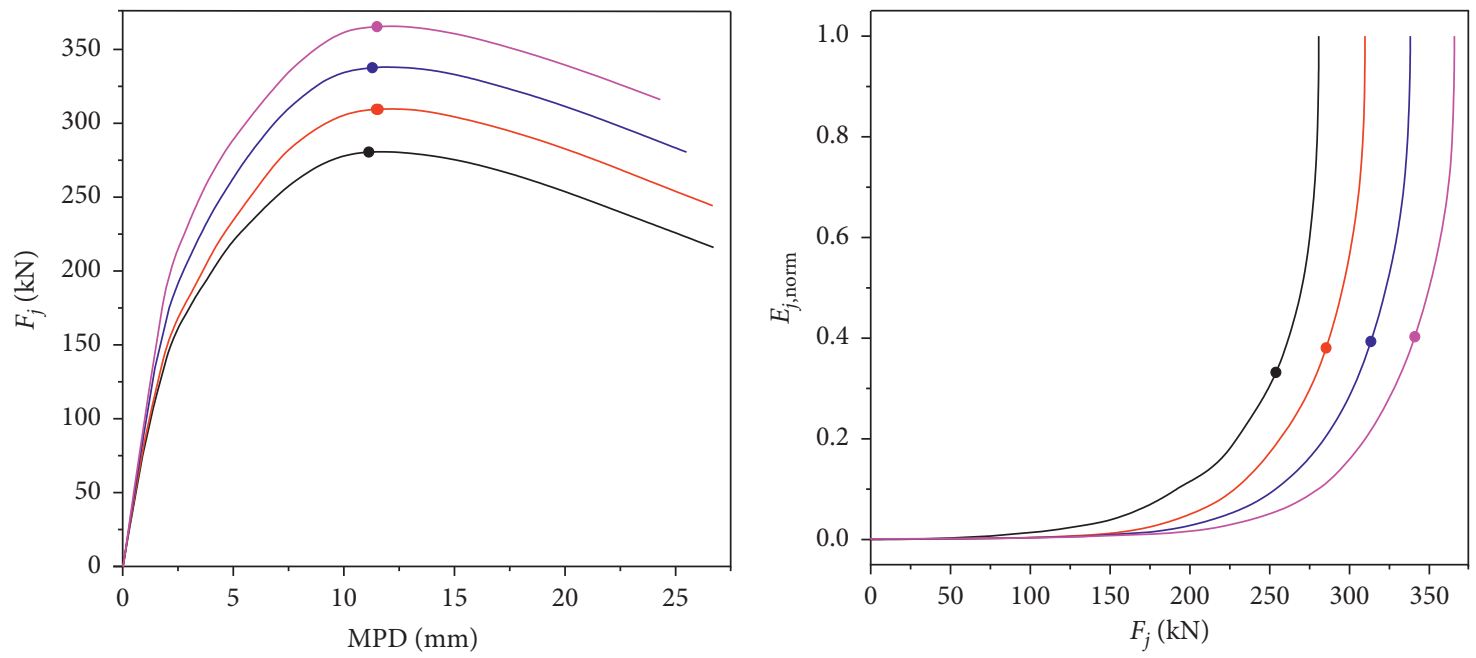

Nominal steel ratio:

$\begin{array}{ll}0.0435 & -0.0741 \\ -0.0586 & -0.0898\end{array}$

(a)

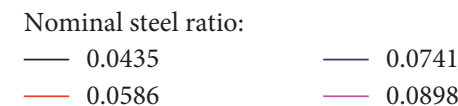

(b)

Figure 18: (a) $F_{j}$ - Middle point deflection of the columns curves under different nominal steel ratio. (b) $E_{j, \text { norm }}-F_{j}$ curves under different nominal steel ratio.

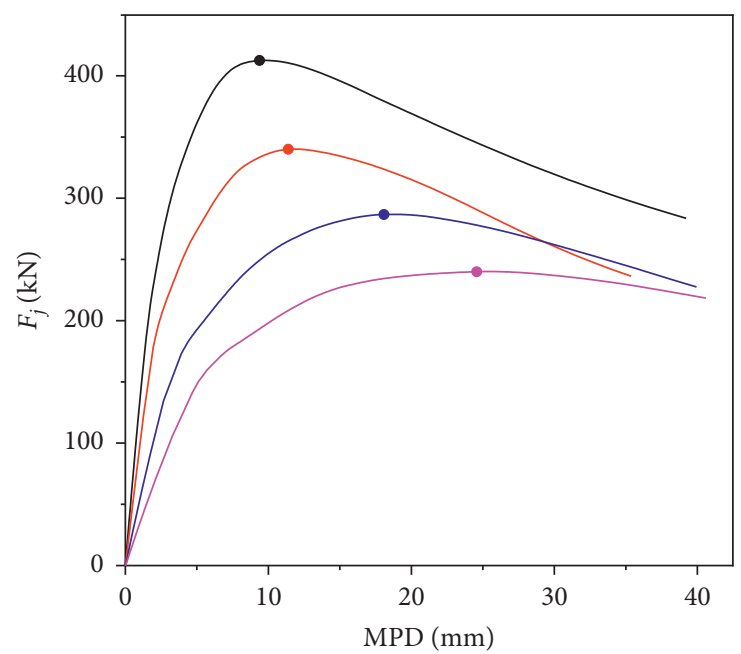

Slenderness ratio:

25.97
-38.95

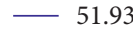

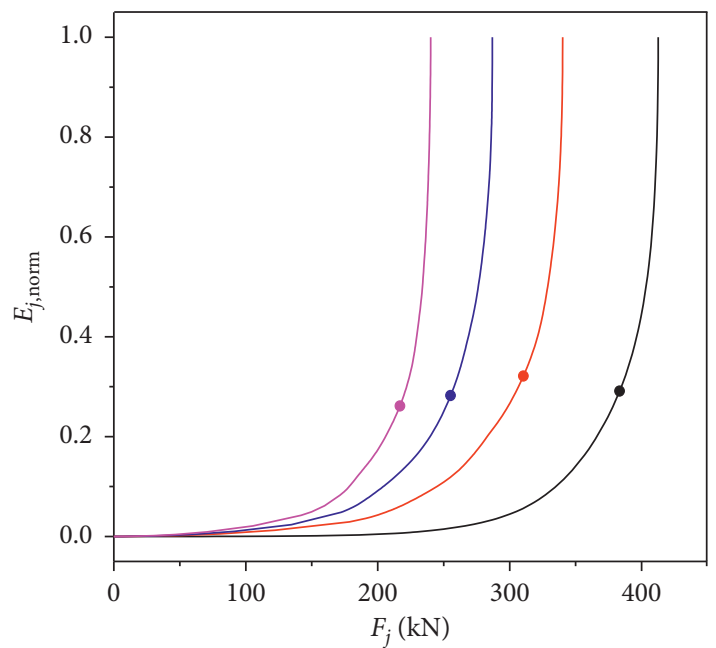

Slenderness ratio:

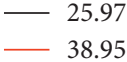

$-51.93$

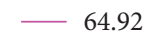

(b)

Figure 19: (a) $F_{j}$ - Middle point deflection of the columns curves under different slenderness ratio. (b) $E_{j \text {,norm }}-F_{j}$ curves under different slenderness ratio. 


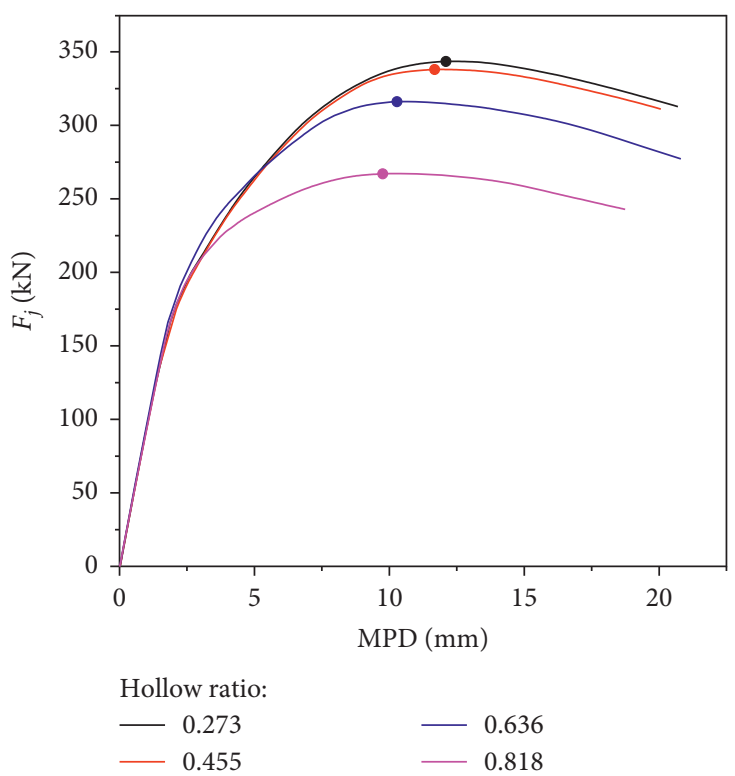

(a)

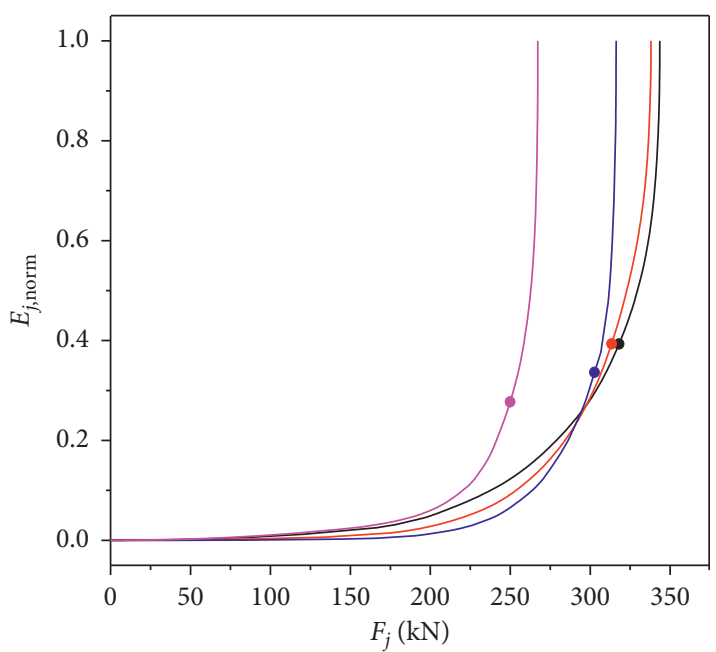

Hollow ratio:

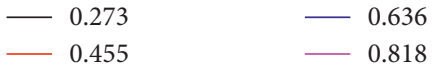

(b)

Figure 20: (a) $F_{j}$ - Middle point deflection of the columns curves under different hollow ratio. (b) $E_{j, \text { norm }}-F_{j}$ curves under different hollow ratio.

$$
\begin{aligned}
& \left\{\begin{array}{l}
\frac{1}{\varphi} \frac{N}{N_{u}}+\frac{a}{d} \frac{M}{M_{u}}=1, \quad \frac{N}{N_{u}} \geq 2 \varphi^{3} \eta_{0} \\
-b\left(\frac{N}{N_{u}}\right)^{2}-c\left(\frac{N}{N_{u}}\right)+\frac{1}{d}\left(\frac{M}{M_{u}}\right)=1, \quad \frac{N}{N_{u}}<2 \varphi^{3} \eta_{0} \\
a=1-2 \varphi^{2} \times \eta_{0} \\
b=\frac{1-\zeta_{0}}{\varphi^{3} \times \eta_{0}^{2}}, \\
c=\frac{2 \times\left(\zeta_{0}-1\right)}{\eta_{0}}, \\
d=1-0.4 \times\left(\frac{N}{N_{E}}\right)
\end{array}\right. \\
& \left\{\begin{array}{l}
N_{E}=\pi^{2} \cdot E_{\mathrm{scm}} \cdot \frac{A_{s c}}{\lambda^{2}}, \\
E_{\mathrm{scm}}=\frac{E_{s} I_{s o}+E_{c} I_{c}+E_{s} I_{s i}}{I_{s o}+I_{c}+I_{s i}}, \\
\zeta_{0}=\left(0.18-0.2 \chi^{2}\right) \xi^{-1.15}+1,
\end{array}\right.
\end{aligned}
$$

$$
\eta_{0}=\left\{\begin{array}{l}
(0.5-0.245 \cdot \xi)\left(-1.8 \chi^{2}+0.2 \chi+1\right), \quad \xi \leq 0.4 \\
\left(0.1+0.14 \cdot \xi^{-0.84}\right)\left(-1.8 \chi^{2}+0.2 \chi+1\right), \quad \xi>0.4
\end{array}\right.
$$

where $\xi$ is constraint effect coefficient; $\chi$ is the slenderness ratio; $N_{u}$ is the axial bearing capacity of the column; $M_{u}$ is the flexural capacity of the column; $E_{s}$ and $E_{c}$ are the modulus elasticity of steel tube and concrete, respectively; $I_{s o}, I_{s i}$ and $I_{c}$ are the section moments of inertia of outer, inner steel tubes, and concrete, respectively; $\varphi$ is the stability coefficient of axial compression; According to the above equation, the ultimate bearing capacity of the column under eccentric compression can be calculated, which is recorded as $N_{1}$. The only difference between the CFSSAST column in this paper and the CFDST column is that the outer steel tube changes from carbon steel to stainless steel, so it is assumed that the relationship between $N_{1}$ and the ultimate bearing capacity of CFSSAST column under eccentric compression $\left(N_{u, p}\right)$ is

$$
N_{u, p}=\beta N_{1} \text {, }
$$

where $\beta$ is fitting coefficient. Since eccentricity and slenderness ratio are the key factors affecting the ultimate bearing capacity, the function $\beta=f(e, \lambda)$ is constructed. Based on numerous researches, $\beta$ is calculated as follows:

$$
\left\{\begin{array}{l}
\beta=\mathrm{Ae}^{2}+\mathrm{Be}+C \\
A=0.0250 \lambda-0.525 \\
B=-0.024 \lambda+0.281 \\
C=-0.0002 \lambda+1.304
\end{array}\right.
$$

where $\lambda$ is the slenderness ratio and $e$ is the eccentricity of load. According to the newly fitted equations, the ultimate 
loads of 171 specimens (17 experimental specimens and 154 simulated specimens) are calculated. Among them, 129 specimens have errors within $5 \%$, accounting for $75.4 \%$, the average error is $0.14 \%$, and the standard deviation is $4.5 \%$.

6.2. Equation for Predicting Failure Load. The equation of failure load is still in the form of ultimate load; that is, the failure load is deduced by using ultimate load. Through parameter analysis, the equation of failure load is as follows:

$$
\left\{\begin{array}{l}
N_{f, p}=\delta N_{1}, \\
\delta=\mathrm{De}^{2}+\mathrm{Ee}+F \\
D=0.0260 \lambda-0.600 \\
E=-0.0260 \lambda+0.388 \\
F=-0.0002 \lambda+1.210
\end{array}\right.
$$

where $\lambda$ is the slenderness ratio and $e$ is the eccentricity of load. The failure loads of 171 specimens (17 experimental specimens and 154 simulated specimens) are calculated by equation (17). Among them, 144 specimens have errors within $5 \%$, accounting for $84.2 \%$, the average error is $0.30 \%$, and the standard deviation is $4.2 \%$. The accuracy of the equations is enough for analysis.

\section{Conclusion}

This study reveals the stressing state characteristics of the CFSSAST columns under eccentric compression and axial compression. Based on the experimental data, the $E_{j, \text { norm }}-$ $F_{j}$ curve is drawn, and then the failure load is determined by Mann-Kendall (M-K) criterion to distinguish the stressing state transition, following the law from quantitative change to qualitative change. The qualitative mutation of the component's stressing state significantly manifests the starting point in the process of the component's failure, so the definition of the existing failure load is updated. The stress distribution of short columns under different loads and the influence of different parameters on the ultimate load and failure load of short columns are analyzed by using simulated data. On the basis of parameter analysis and related research, the failure load and ultimate load equations of CFSSAST columns are fitted. Those provide references for the improvement of relevant design codes.

\section{Data Availability}

The data used to support the findings of this study are available from the corresponding author upon request.

\section{Conflicts of Interest}

The authors declare that there are no conflicts of interest regarding the publication of this paper.

\section{Authors' Contributions}

Sijin Liu, Wei Wang, and Baisong Yang conceived the study and were responsible for the design and development of the data analysis. Wei Wang and Sijin Liu were responsible for data collection, analysis, and interpretation. Lingxian Yang and Guorui Sun helped perform the analysis with constructive discussions. Baisong Yang wrote the original draft of the article. Baisong Yang and Wei Wang equally contributed to this manuscript as co first author.

\section{Acknowledgments}

The authors would like to express their gratitude to Xiaofei Wen for carrying out the excellent experiment of CFSSAST columns and giving the complete experimental data. The authors would also like to thank the members of the HIT 504 office for their selfless help and useful suggestions.

\section{References}

[1] Z. Tao, L. H. Han, and H. Huang, "Mechanical behavior of concrete filled double skin steel tubular columns with circular cular sections," China Civil Engineering Journal, vol. 37, no. 10, pp. 41-51, 2004.

[2] J. H. Zhao and J. Wei, "Analysis of ultimate bearing of concrete filled double skin steel tubular columns," Sciencepaper Online, vol. 2, no. 9, pp. 688-692, 2007.

[3] L. Zhang, X. G. Wang, and Y. C. Han, "Experiment analysis of concrete filled circular steel tubular columns under eccentric load," Journal of Railway Science and Engineering, vol. 7, no. 5, pp. 50-53, 2010.

[4] Q. X. Ren, Y. B. Lv, L. G. Jia, and D. Q. Liu, "Preliminary analysis on inclined concrete-filled steel tubular stub columns with circular section under axial compression," Applied Mechanics and Materials, vol. 88-89, pp. 46-49, 2011.

[5] W. Li, L.-H. Han, and X.-L. Zhao, "Axial strength of concretefilled double skin steel tubular (CFDST) columns with preload on steel tubes," Thin-Walled Structures, vol. 56, pp. 9-20, 2012.

[6] K. Uenaka, H. Kitoh, and K. Sonoda, "Concrete filled double skin circular stub columns under compression," Thin-Walled Structures, vol. 48, no. 1, pp. 19-24, 2010.

[7] Y. Z. Wang and B. S. Li, "Axial behavior of concrete-filled double skin steel tubular stub columns filled with demolished concrete lump," Advanced Materials Research, vol. 898, pp. 407-410, 2014.

[8] M. Pagoulatou, T. Sheehan, X. H. Dai, and D. Lam, "Finite element analysis on the capacity of circular concrete-filled double-skin steel tubular (CFDST) stub columns," Engineering Structures, vol. 72, no. 1, pp. 102-112, 2014.

[9] M. F. Hassanein and O. F. Kharoob, "Compressive strength of circular concrete-filled double skin tubular short columns," Thin-Walled Structures, vol. 77, pp. 165-173, 2014.

[10] Q. Q. Liang, "Numerical simulation of high strength circular double-skin concrete-filled steel tubular slender columns," Engineering Structures, vol. 168, pp. 205-217, 2018.

[11] L. H. Han, Q. X. Ren, and W. Li, "Tests on stub stainless steelconcrete-carbon steel double-skin tubular (DST) columns," Journal of Constructional Steel Research, vol. 63, no. 3, pp. 473-452, 2011.

[12] X. Chang, Z. Liang Ru, W. Zhou, and Y.-B. Zhang, "Study on concrete-filled stainless steel-carbon steel tubular (CFSCT) stub columns under compression," Thin-Walled Structures, vol. 63, pp. 125-133, 2013. 
[13] M. Cao, Flexural Behavior of Stainless Steel-Concrete-Steel Concrete Filled Double Skin Steel Tube, M.S. thesis, Taiyuan University of Technology, Taiyuan, China, 2015.

[14] F. Zhou and W. Xu, "Cyclic loading tests on concrete-filled double-skin (SHS outer and CHS inner) stainless steel tubular beam-columns," Engineering Structures, vol. 127, pp. 304-318, 2015.

[15] X. F. Wen, Experimental and Theoretical Analysis of Mechanical Behavior of Concrete-Filled the Gap between Stainless Steel and Steel Tubular Columns, M.S. thesis, Taiyuan University of Technology, Taiyuan, China, 2017.

[16] J. G. Zhang, F. F. Liu, and T. J. Zhao, "Experimental research on the shear resistance performance of concrete-filled double stainless-steel tubular columns," Journal of Harbin Engineering University, vol. 40, no. 7, pp. 1311-1318, 2019.

[17] S. Jiang and R. Wang, "Experiment study and finite element analysis of concrete filled stainless and steel double skin tubes member under lateral impact," Industrial Construction, vol. 46, no. 11, pp. 161-167, 2016.

[18] H. Zhao, R. Wang, C. C. Hou, and D. Lam, "Performance of circular CFDST members with external stainless steel tube under transverse impact loading," Thin-Walled Structures, vol. 145, 2019.

[19] G. C. Zhou, M. Y. Rafiq, G. Bugmann, and D. J. Easterbrook, "Cellular automata model for predicting the failure pattern of laterally loaded masonry wall panels," Journal of Computing in Civil Engineering, vol. 20, no. 6, pp. 400-409, 2006.

[20] G. Zhou, D. Pan, X. Xu, and Y. M. Rafiq, "Innovative ANN technique for predicting failure/cracking load of masonry wall panel under lateral load," Journal of Computing in Civil Engineering, vol. 24, no. 4, pp. 377-387, 2010.

[21] F. Chen, Nonlinear Static Wind Stability Analysis of Long Span Concrete Filled Steel Tubular Arch Bridge, Ph.D. Thesis, Chang'an University, Xian, China, 2003.

[22] L. H. Han, Concrete Filled Steel Tubular Structures: Theory and Practice, Science Press, Beijing, China, 2004.

[23] Z. H. Guo, Strength and Constitutive Relation of Concrete: Principle and Application, China Construction \& Industry Press, Beijing, China, 2004. 